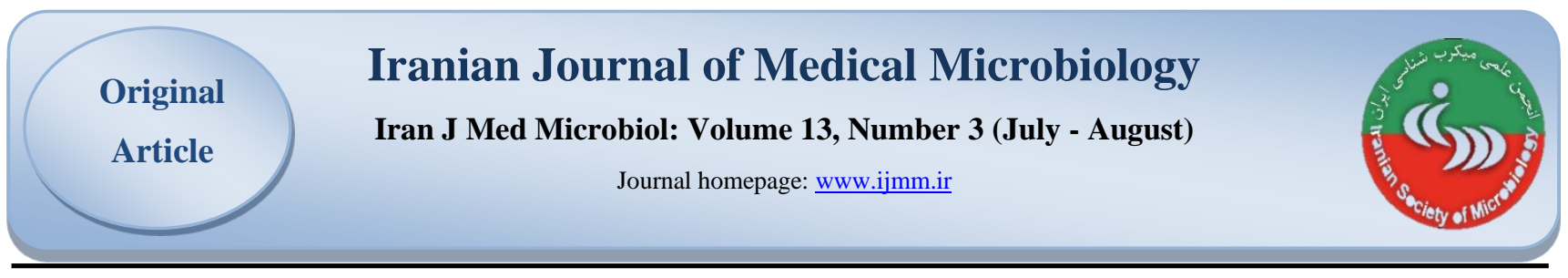

\title{
Evaluation of Antibiotic Resistance Pattern of Meropenem and Piperacillin- Tazobactam in Multi Drug Resistant Acinetobacter baumannii Isolates by Flow Cytometry Method
}

\author{
Nahid Rahimi ${ }^{1}$, Sahar Honarmand Jahromy*2, Shohreh Zare Karizi ${ }^{3}$
}

1. MSc Student, Department of Microbiology, School of Biological Sciences, Varamin- Pishva Branch, Islamic Azad University, Varamin, Iran

2. Assistant Professor, Department of Microbiology, School of Biological Sciences, Varamin-Pishva Branch, Islamic Azad University, Varamin, Iran

3. Assistant Professor, Department of Genetics, School of Biological Sciences, Varamin-Pishva Branch, Islamic Azad University, Varamin, Iran

\section{Article Information}

\section{Article Subject: \\ Antibiotic Resistance \\ d. \\ 10.30699/ijmm.13.3.194}

Corresponding author:

Sahar Honarmand Jahromy, Assistant Professor, Department of Microbiology, School of Biological Sciences, VaraminPishva Branch, Islamic Azad University, Varamin, Iran

Email:

sahar_hj2@yahoo.com

Use your device to scan and read the article online

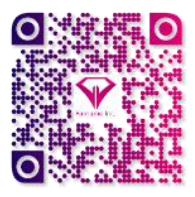

\section{Abstract}

Background and Aims: Flow cytometry is a rapid method that can analyze thousands of cells per second and can be used for determination of microbial populations and determination of bacterial antimicrobial susceptibility. In this study antibiotic resistance pattern of Acinetobacter baumannii isolates by flow cytometer was evaluated.

Materials and Methods: 55 isolates of $A$. baumannii were isolated from clinical specimen of patients and were identified by biochemical tests. Antibiotic resistance patterns were studied by disc diffusion method and MDR strains were selected. MIC of Meropenem -Tazobactam and Piperacillin were determined. Also antibiotic resistance pattern of isolates was determined by coloring with Rhodamine-123 and flow cytometry. Excel software and STDV test were used to calculate the standard deviation of antibiotic resistance and MIC results.To evaluate the agreement between the results of antibiotic resistance pattern using disk diffusion methods and the MIC and Flow cytometry category agreement was used.

Results: $98 \%$ of isolates were MDR. The MIC ranges for maropenem were $8-256$ $\mu \mathrm{g} / \mathrm{mL}$ and for Piperacilllin-tazobactam were $128-1024 \mu \mathrm{g} / \mathrm{mL}$. By flow cytometry it was demonstrated that at concentrations of 8,4 and $2 \mu \mathrm{g} / \mathrm{mL}$ of meropenem, only $1.96 \%, 1.44 \%$ and $0.59 \%$, of cells were killed respectively. At concentrations of 64,128 and $16 \mu \mathrm{g} / \mathrm{mL}$ of piperacillin, $13.8 \%, 11.3 \%$ and $5.9 \%$ of cells were killed respectively. Reducing the number of living bacteria was observed with increasing concentrations of both antibiotics.

Conclusion: The similarity between the results of flow cytometry and both agar and broth antibacterial susceptibility methods showed flow cytometry as a reliable and rapid test that can be used for this purpose.

Keywords: Antibiotic susceptibility, MDR, Acinetobacter baumannii, flow cytometer

Received: 2019/08/09 Accepted: 2019/10/02 Available online: 2019/10/02

Copyright $\odot$ 2019. This is an open-access article distributed under the terms of the Creative Commons Attribution- 4.0 International License which permits Share, copy and redistribution of the material in any medium or format or adapt, remix, transform, and build upon the material for any purpose, even commercially.

How to cite this article:

Rahimi N, Honarmand Jahromy S, Zare Karizi S. Evaluation of Antibiotic Resistance Pattern of Meropenem and Piperacillin- Tazobactam in Multi Drug Resistant Acinetobacter baumannii Isolates by Flow Cytometry Method. Iran J Med Microbiol. 2019; 13 (3) :194-209

Download citation:

BibTeX $|\underline{\text { RIS }}| \underline{\text { EndNote }}|\underline{\text { Medlars }}| \underline{\text { ProCite }}|\underline{\text { Reference Manager }}| \underline{\text { RefWorks }}$ Send citation to:

9 Mendeley 2 Zotero $\forall$ RefWorks 


\section{Introduction}

Standard Antibiotic Susceptibility Test (AST) include disk diffusion, broth dilution and manual and automated alternative methods that take 18 to 24 hours to get a good result. Faster methods such as DNA and mass spectrometry-based methods do not always provide good information in antibiotic susceptibility and have limitation $(11,12)$. This limitation can be achieved by means of a device based on identification of bacterial physiological changes in the presence of antibiotics and by using biodegradable fluorescent markers, as flow cytometry $(14,15)$. Flow cytometry (FCM), is a device that passes cells or micrometer particles through the point of contact where the laser beams affect them, and the light that they absorb which is based on the intrinsic or sub-physical properties of the particle itself, Scatter or diffuse, and this light can be measured $(1,2)$. Today, flow cytometry is a tool for bacterial analysis, detection, enumeration, determining changes in cellular function, metabolic activity, cell viability and antibiotic susceptibility of bacteria $(3,32)$. Over the past decade, the presence of Acinetobacter baumannii, especially multiple drug resistant $A$. baumannii (MDRAB), has been recognized as the most important pathogen and cause of hospital mortality worldwide. Rapid identification of these strains is essential for the treatment of their disease $(17,18)$. The aim of this study was to investigate the antibiotic resistance pattern of multidrug-resistant $A$. baumannii isolates against meropenem and piperacillin-tazobactam using flow cytometry.

\section{Methods}

This cross-sectional descriptive study was performed on 55 A. baumannii strains randomly isolated from clinical specimens of 230 patients admitted to Milad Hospital, Tehran, from November to April 2017. Gram staining and biochemical tests were used for identifying A. baumannii strains. Antibiotic susceptibility testing was performed by disk diffusion methods according to CLSI 2017 against 7 antibiotics (Table 1). Strains that were resistant to more than two classes of antibiotics were included as MDR strains. Microdilution broth method was used to determine Minimum Inhibitory Concentration of meropenem and piperacillintazobactam. For Flow cytometry 10 isolates of multidrug-resistant $A$. baumannii were selected. The concentrations of meropenem and piperacillintazobactam for $A$. baumannii isolates were 2, 4, 8 $\mu \mathrm{g} / \mathrm{mL}$ and $16,64,128 \mu \mathrm{g} / \mathrm{mL}$. The incubation time of antibiotic treatment on bacterial suspension was 4 hours. Then the suspension was centrifuged and stained by $2 \mu \mathrm{g} / \mathrm{mL}$ of Rhodhamin 123 florescent dye. The results were analyzed by Flow cytometer FACSCalibur using Side scatter (SSC), forward scatter (FSC) and green florescent light (FL1) parameters with 488-nm wavelength helium laser beam. Data analysis was performed for all methods.

Table 1. Antibiotic resistance pattern of Acinetobacter baumannii isolates based on according to the CLSI 2017

\begin{tabular}{|c|c|c|c|c|c|}
\hline Antimicvobial Agent & SYMBOL & DISK $(\boldsymbol{\mu g})$ & $\mathbf{S}$ & I & $\mathbf{R}$ \\
\hline Meropenem (Carbapenem) & $(\mathrm{MEN})$ & 10 & $>23$ & 20_22 & $<19$ \\
\hline Ciprofloxacin(FLUOROQUINOLONES & $(\mathrm{CP})$ & 5 & $>21$ & $2 \_6$ & $<15$ \\
\hline Gentamycin(AMINOGLYCOSIDES ) & $(\mathrm{GM})$ & 10 & $>15$ & $13 \_14$ & $<12$ \\
\hline Piperacillin-Tazobactam(Beta lactam) & (Pip- T) & $100 / 1$ & $>21$ & 18_20 & $<17$ \\
\hline levofloxacin (FLUOROQUINOLONES & $(\mathrm{LVF})$ & 5 & $>16$ & 11_15 & $<10$ \\
\hline Tetracyclin (Tetracycline ) & (TE) & 30 & $>15$ & $12 \_14$ & $<11$ \\
\hline Imipenem (Carbapenem) & (IMP) & 10 & $>18$ & 14_17 & $<13$ \\
\hline
\end{tabular}

\section{Results}

The average antibiotic resistance of $A$. baumannii strains to meropenem, ciprofloxacin, gentamicin, piperacillin -tazobactam, levofl- oxazine, tetracycline and imipenem were $100 \%$, $95.7 \%, 72.8 \%, 100 \%, 100 \%, 65.7 \%$ and $94.2 \%$, respectively (Figure 1). $98 \%$ of A. baumannii isolates were included as MDR strains. 


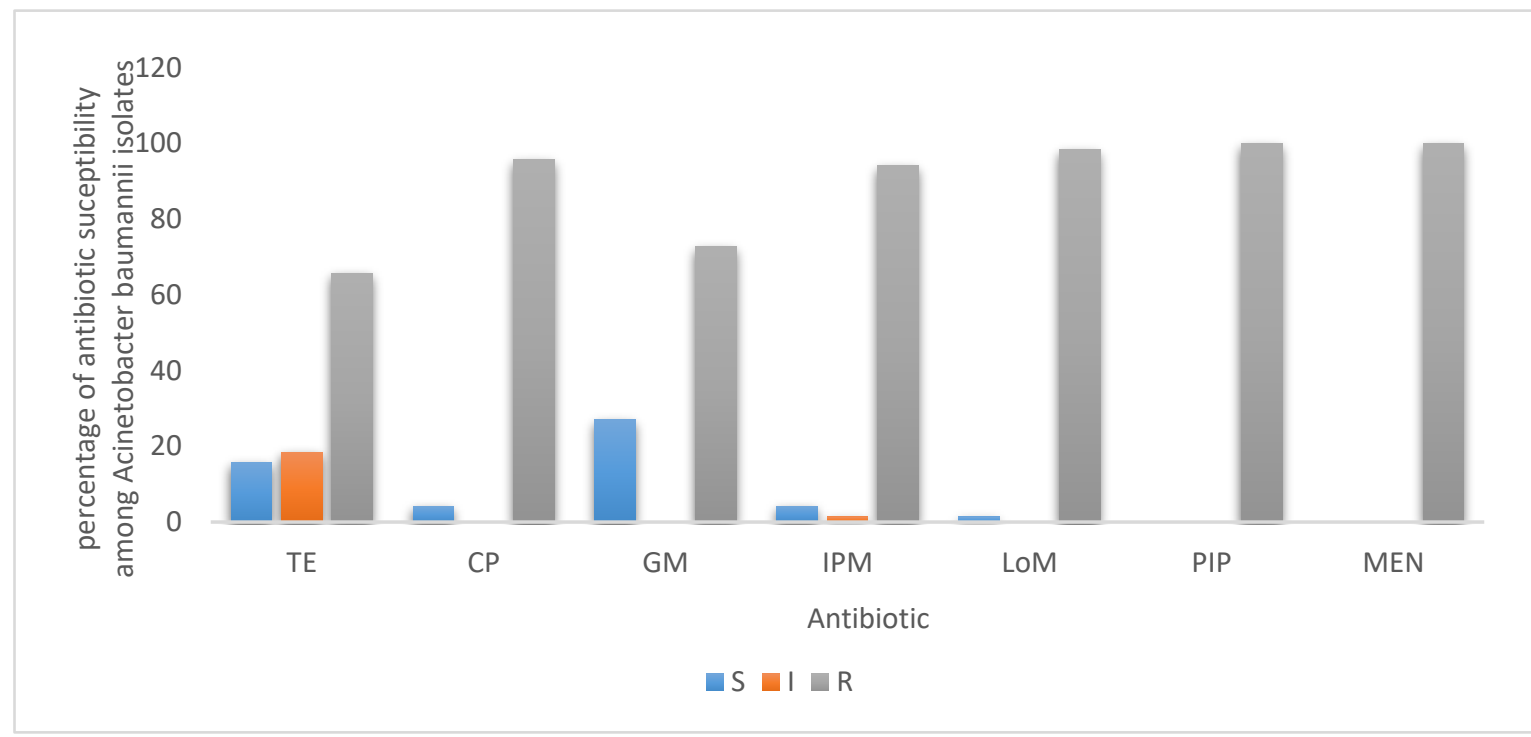

Figure1: Antibiotic resistance profile of Acinetobacter baumannii isolates
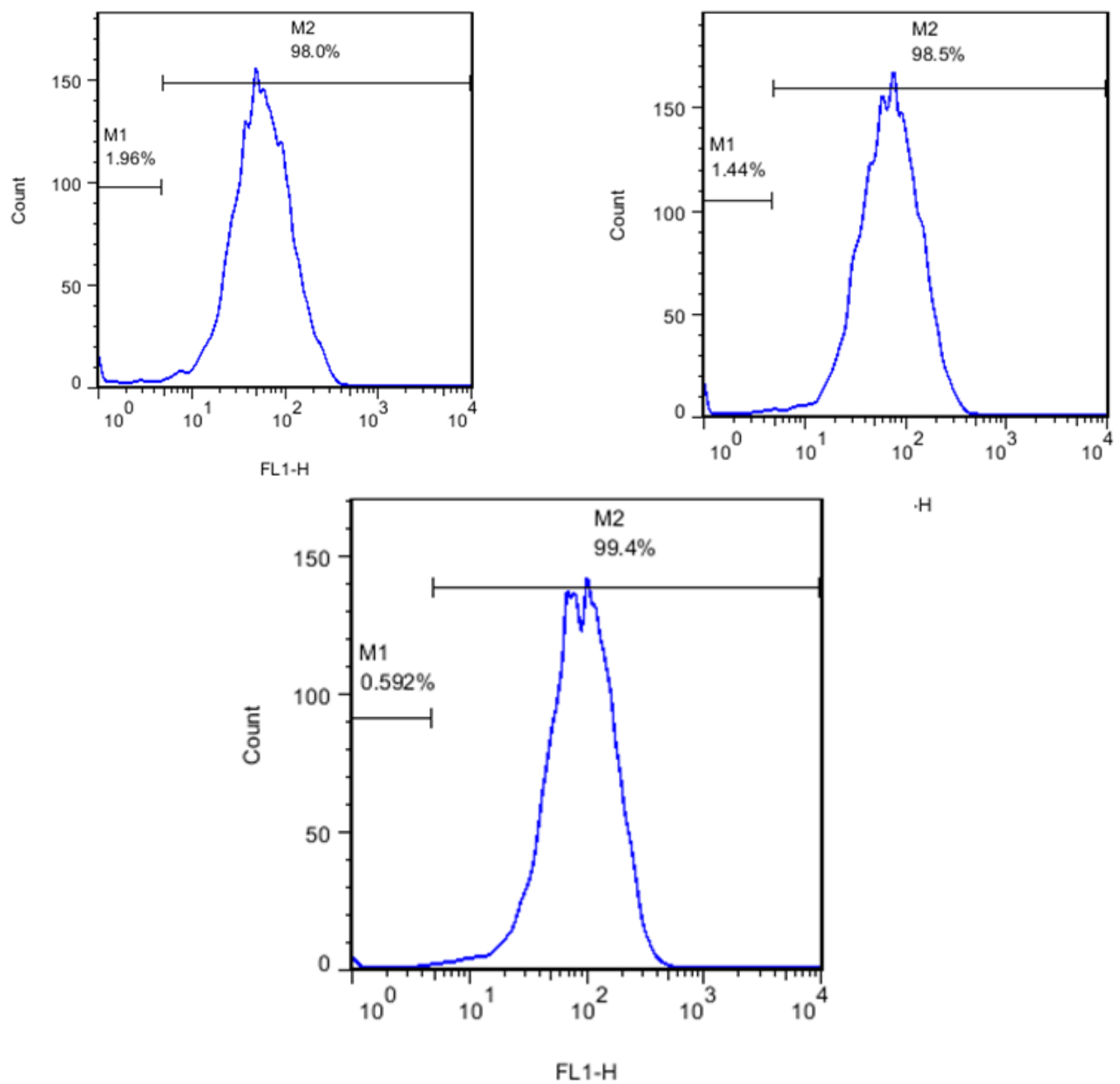

Figure 2. Histogram of Flow cytometry analysis for meropenem 

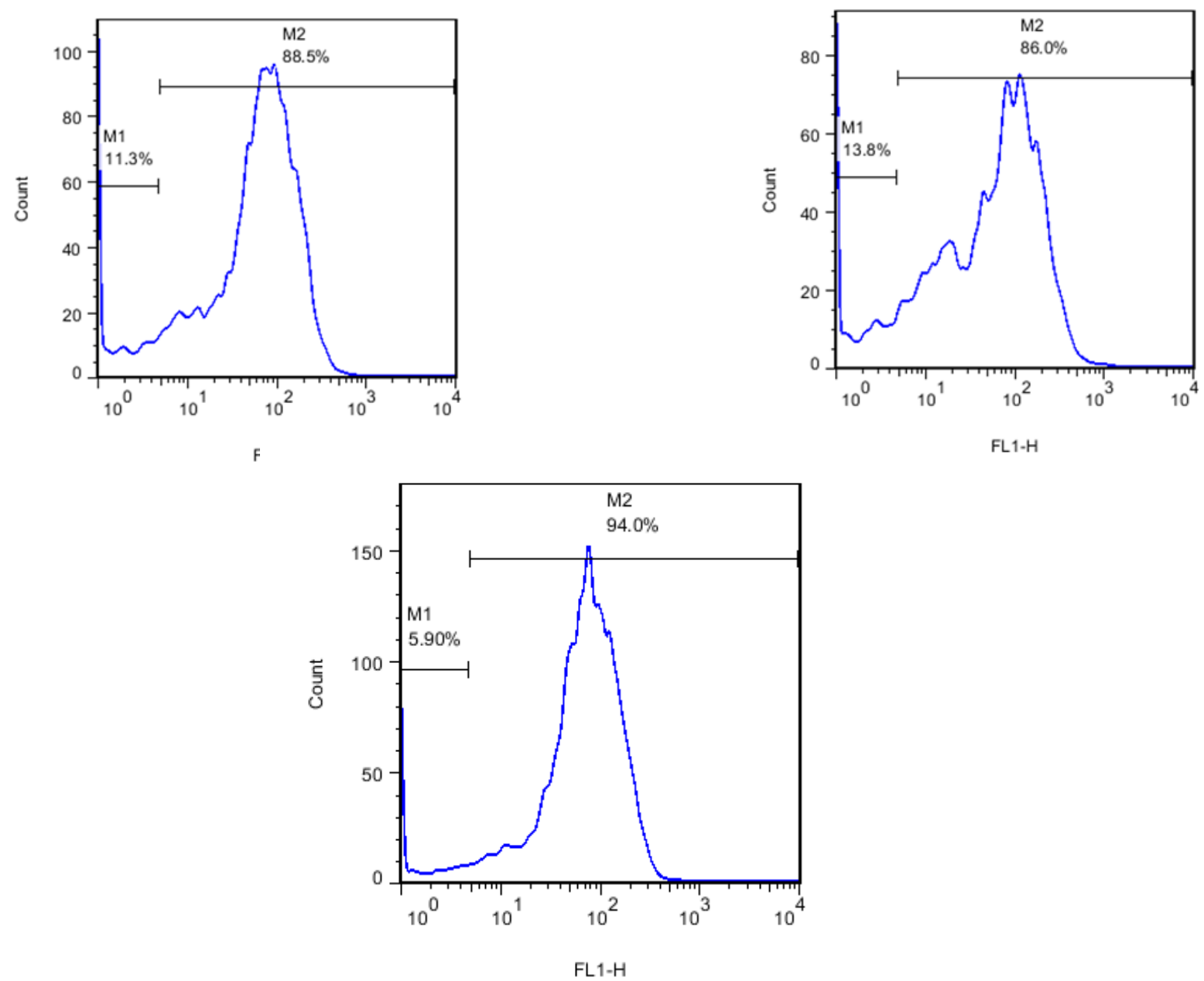

Figure3. Histogram of Flow cytometry analysis for Piperacilin -Tazobactam

TThe results of antibiotic MIC of isolates showed that the mean MIC of Meropenem antibiotic was 105.14 with a standard deviation of 84.101 and for the piperacillin-tazobactam antibiotic 1236.11 with a standard deviation of $774.124 .37 / 37 \%$ of the strains had MIC $64 \mu \mathrm{g} / \mathrm{mL}$ for Micropenem and only 90/90\% of isolates had MIC of $8 \mu \mathrm{g} / \mathrm{mL}$. For piperacillin-tazobactam the highest MIC was $1024 \mu \mathrm{g} / \mathrm{mL}$ and higher.

In Flow cytometry section at concentrations of 2, 4 and $8 \mu \mathrm{g} / \mathrm{ml}$ of meropenem antibiotic, the cell death rate was $1.96 \%, 1.44 \%$ and $0.59 \%$, respectively (Figure 2).

At concentrations of 16,64 and $128 \mu \mathrm{g} / \mathrm{mL}$ of piperacillin-tazobactam antibiotic, the cell death rate was $1.96 \%, 1.44 \%$ and $0.59 \%$, respectively (Figure 2).
The results of flow cytometry to determine the resistance pattern of $10 \mathrm{MDR}$ isolates of $A$. baumannii, showed that more than $98 \%$ of cells survived the effects of meropenem and piperacillin-tazobactam and all isolates showed resistance to meropenem and piperacillin tazobactam. Comparison of the results of antibiotic resistance pattern determination with all three methods and the Category agreement (CA) between methods were finally $100 \%$ for both antibiotics.

\section{Discussion}

Previous studies in Iran have shown that carbapenem resistance of $A$. baumannii strains is increasing. In a systematic study by Moradi et al. In 2015, the rate of resistance to meropenem and imipenem antibiotics between 2001- 2007 increased by $64.3 \%$ and $51.1 \%$ to $81.5 \%$ and 
76.5\% between 2012 and 2013, respectively (24). Excessive resistance to carbapenem, which was also reported $100 \%$ in this study, is a serious alarm for the treatment of infections associated with $A$. baumannii. One of the most important reasons is using inappropriate antibiotics. Also, quick and accurate tests to determine the antibiotic susceptibility of the bacteria and the need for rapid administration of an initial antimicrobial empirical treatment is very important when the physician is awaiting the results of sensitivity testing with standard time-consuming. Flow cytometry can analyze diverse microbial populations in a suspension and showing microbial diversity in a short time. In this study the results obtained by flow cytometer in measuring antibiotic resistance pattern were obtained 4 hours after preparation of microbial suspension resulting from overnight culture on bacterial colonies. More than $98 \%$ of bacterial cells survived after exposure to different concentrations of meropenem and piperacillintazobactam that was in agreement with the results of disk diffusion and MIC method for determination of antibiotic resistance pattern of $A$. baumannii isolates (CA 100\%). This illustrates the importance of using a flow cytometer as a rapid and sensitive method to determine the antibiotic resistance pattern of bacterial isolates. However, the use of other antibiotics such as gentamicin, which in this study showed less resistance, and the determination of antibiotic resistance pattern of higher number of bacterial strains by flow cytometry is suggested in future studies.

\section{Acknowledgments}

The authors would like to thank Mr. Omid Hosseini, technician of Research Laboratory of Shahid Beheshti University who helped them in this study.

\section{Conflict of Interest}

The authors reported no conflict of interest. 


\section{بررسى الكوى مقاومت نسبت به آنتىبيوتيكهاى مروينم و يِيِيراسيلين-تازوباكتام در جدايههاى اسينتوباكتر بومانى مقاوم جند دارويى با روش فلوسايتومترى}

ناهيد رحيمى'، سحر هنرمند جهر مى rّ"، شهره زارع كاريزى"

'. . دانشجوى كارشناسى ارشد،كروه ميكروبيولوزى، دانشكده علوم زيستى، دانشكاه آزاد اسلامى واحد ورامين - بيشوا، ورامين، ايران

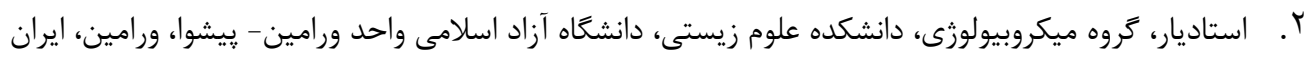

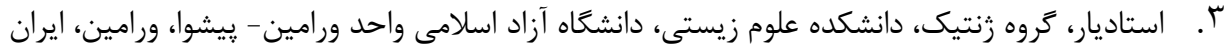

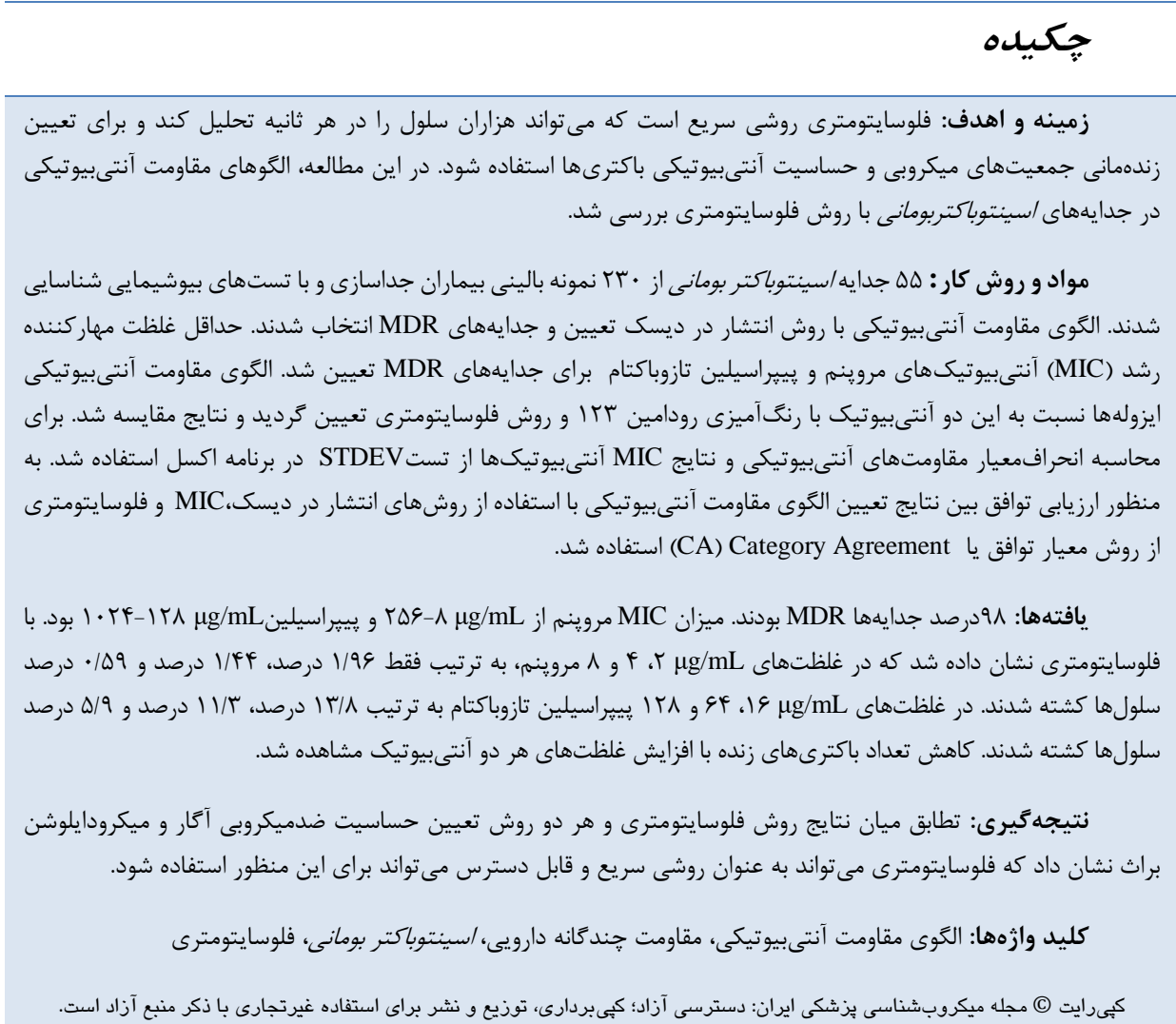

اطلاعات مقاله - 2 - اله

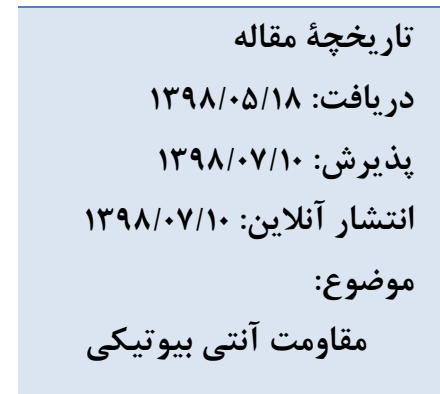

IJMM1398;13(3): 194-209

نويسنده مسئول:

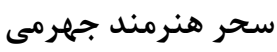
استاديار، گروه ميكروبيولوزى، دانشكده علوم

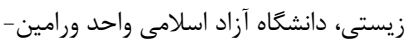
پِيشوا، ورامين، ايران دان

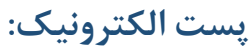
sahar_hj2@yahoo.com
آزمايشگاهى براى ييوند اعضاء و تشخيص بيماريهاى عفونى به خود

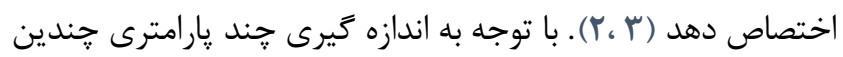
هزار سلول منفرد در هر ثانيه توسط فلوسايتومتر، اين وسيله به عنوان

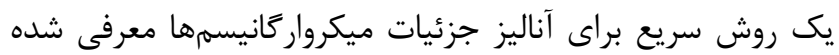

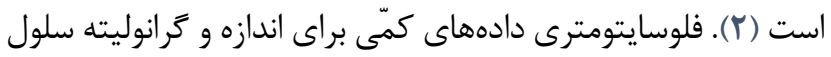
را از طريق يارامتر سيخنالهاى light scattering و اطلاعات كمّى ئى سيخنالهاى فلورسنس روى سطح آنتىرنها يا اجزاى درونسلولى ليى
فلوسايتومترى FCM يا Flow cytometry) دستگاهى است كه سلولها يا ذرات ميكرومترى را از نقطه ى تماسى كه اشعه ليزر روى ئوى آنها اثر مى حذارد عبور داده و نورى كه ذرات جذب مى كنند بر اساس خصوصيات ذاتى يا فرعى فيزيكى خود ذره، يراكنده يا منتشر مى شعود و اين نور قابل اندازهگيرى است (1). سرعت و دقت بالاى اين تكنيك، موجب شد تا خيلى زود جايگاه ويزهاى رادر رشته رهاى مختلفى جون

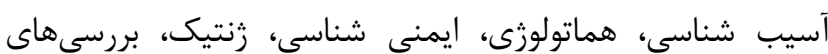


جهشهاى مقاومت و زنهاى مقاومت نيز هستند كه قادر به زنده

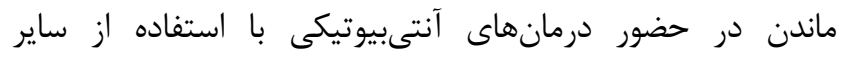

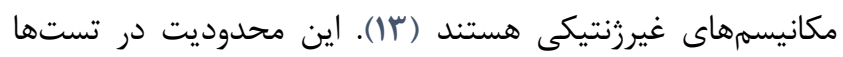

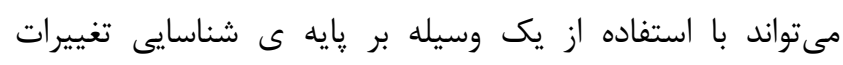

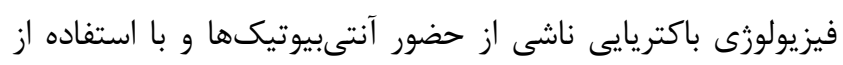

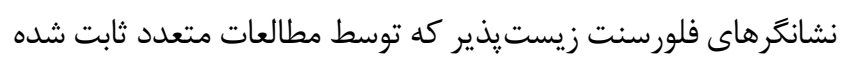

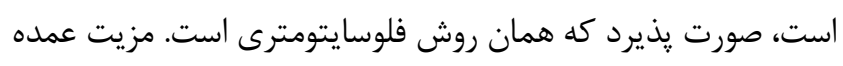

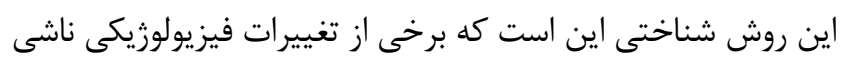

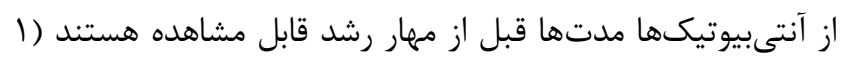

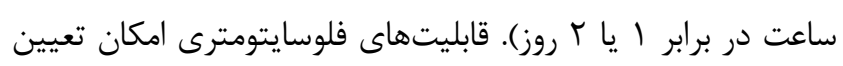

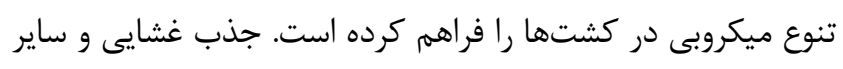

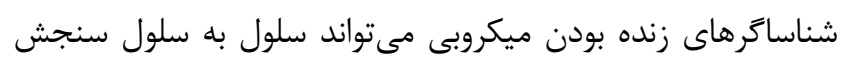

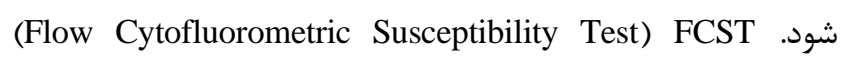
ياسخهاى سلولى را در مقابل اثرات محيطى و تركيبات مختلف

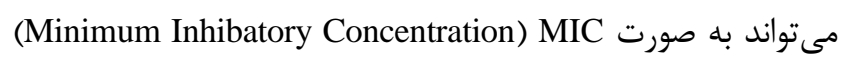
(Minimium Bactericidal concentration ) MBC,

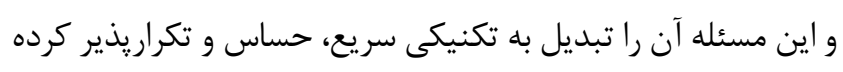

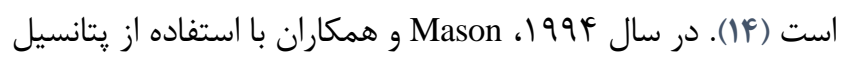

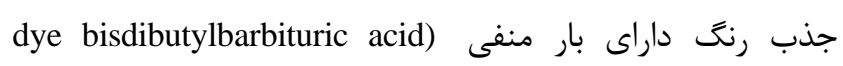
جنtrimethine oxonol

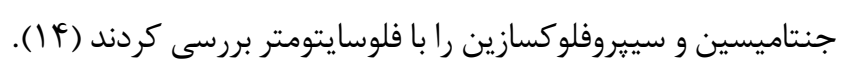

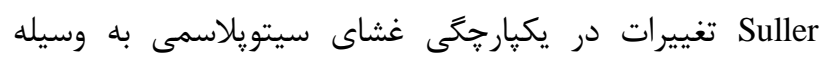

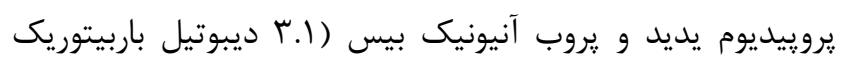

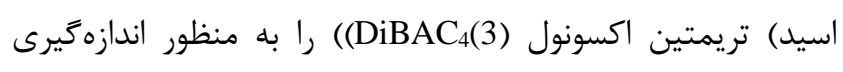

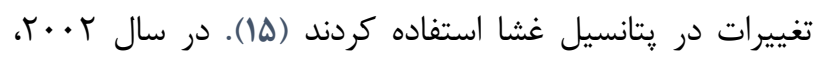

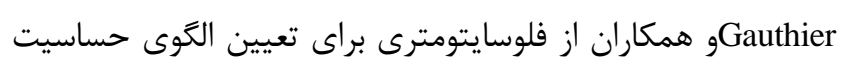

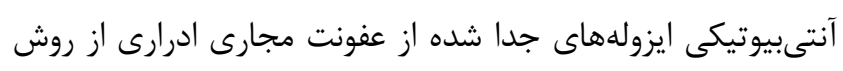

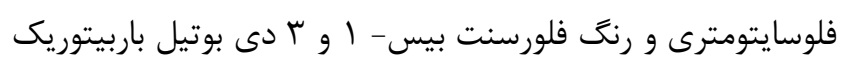

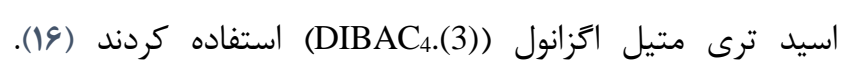
Nuding

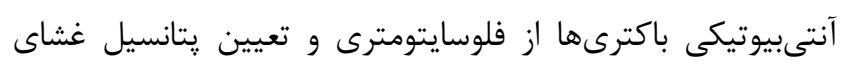
باكتريايى استفاده كردند (Y).

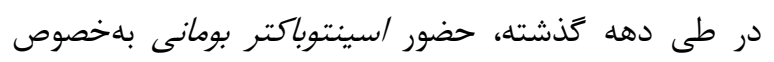

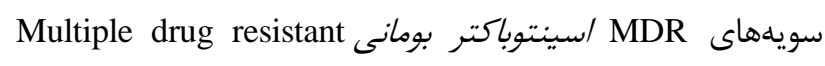
(MDRAB) Acinetobacter baumannii بيمارىزا و مركىمير بيمارستانى در سراسر دنيا شناخته شده است

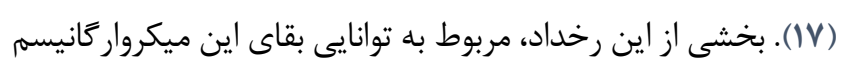

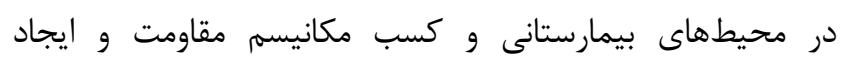

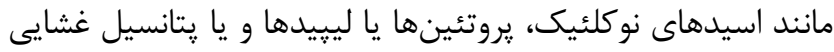

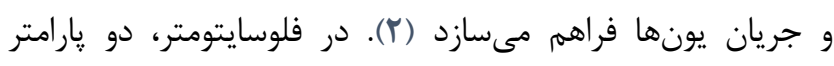
light scatter

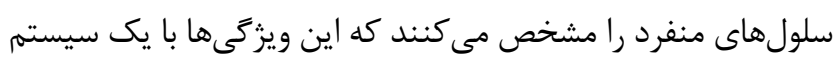

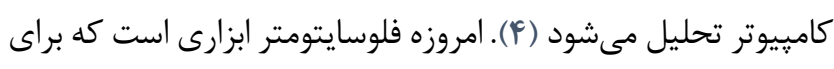
تحليل باكتريايى از تشخيص و شمارش باكترى تا تعيين تغييرات در

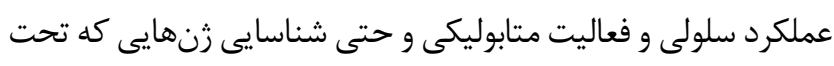

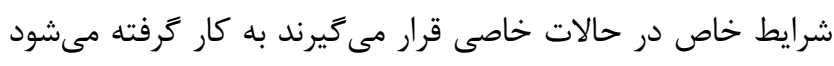

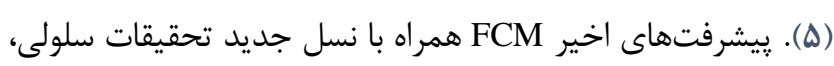

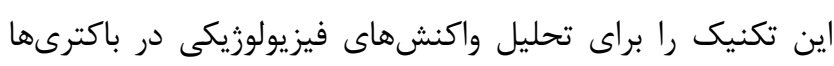

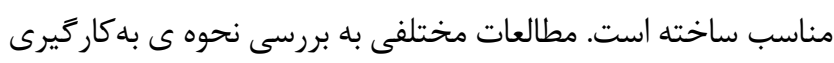

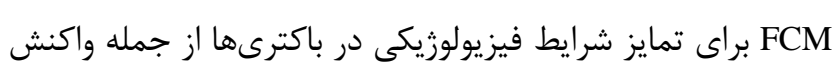

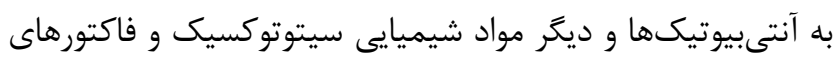

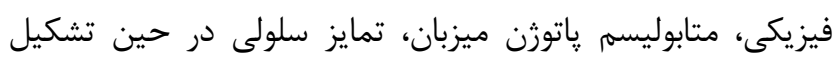
بيوفيلم و مكانيسمهاى هدايت رشد و توسعه مى مسيرهايى مانند

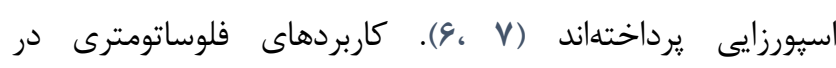

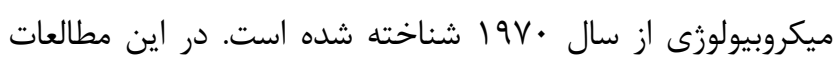

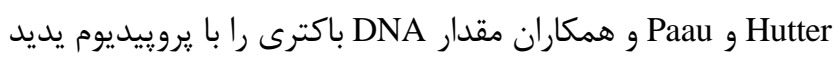

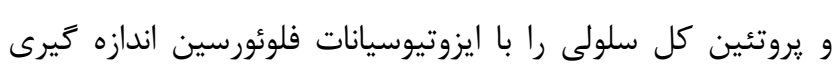

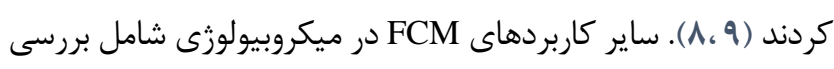

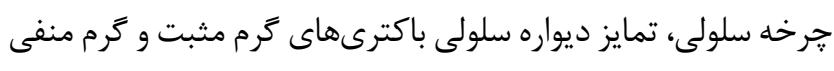

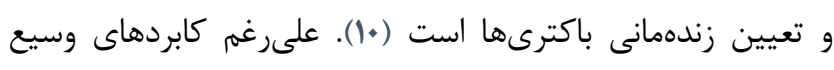

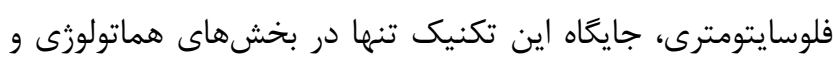

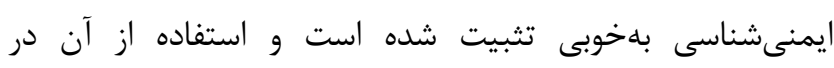
ميكروبيولوزى بالينى هنوز نادر است. روش هاى استاندارد تست حساسيت آنتىبيوتيك ( Antibiotic

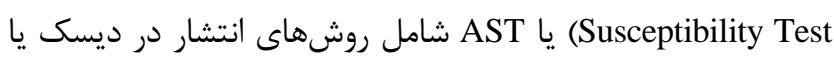
رقت در محيط مايع و روشهاى جايكزين دستى و خودكار مانند ETest 2 و لن 2 VITEK

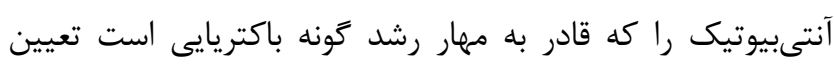

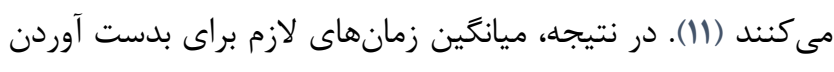

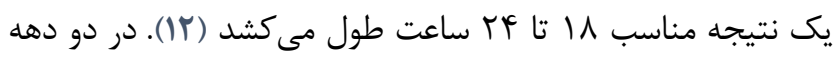

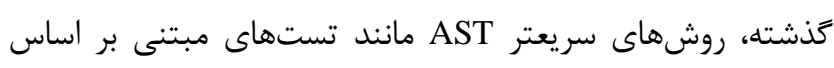

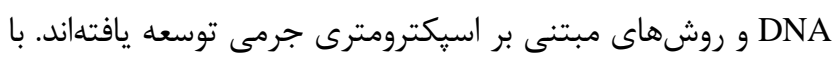

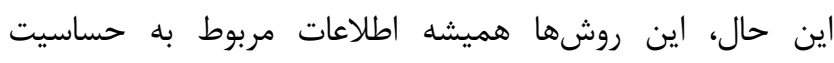

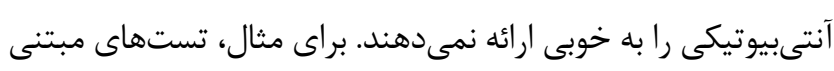

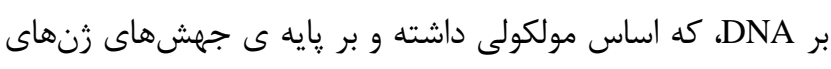
مقاومت هستند خيلى مناسب نيستند. علاوه بر اين، باكترى دهاى فاقئ فاقد 
كرمخانهَذارى با رنغَآميزى كرم و آزمونهاى بيوشيميايى استاندارد

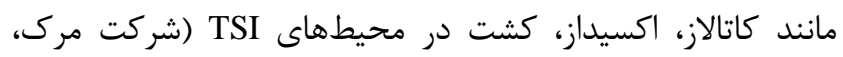
آلمان)، MRVP (شركت مرك، آلمان)، اوره (شركت مرك، آلمان)، و و

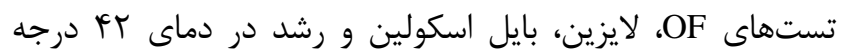

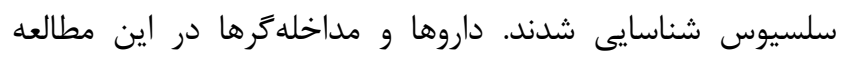
استفاده نشد.

تست تعيين حساسيت آنتىبيوتيكى و تعيين سويههاى

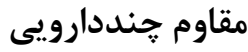

تست تعيين حساسيت آنتىبيوتيكى (آنتىبيوكرام) به روش

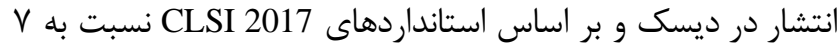

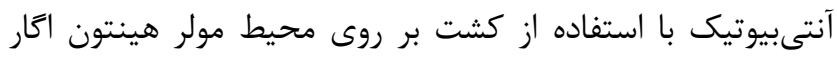

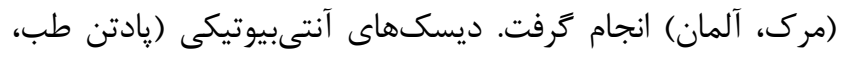

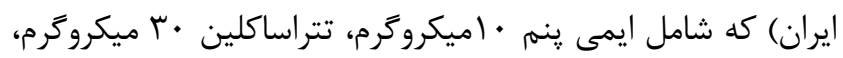

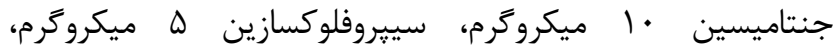

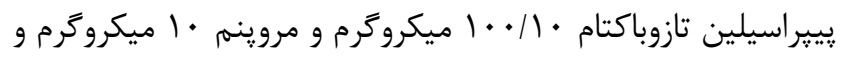

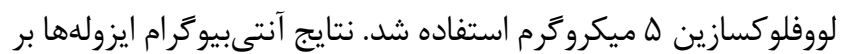
اساس استاندارد CLSI2017 و با توجه به اندازه قطر هاله عدم رشد التد

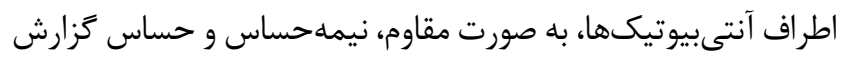

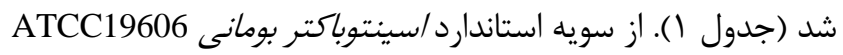

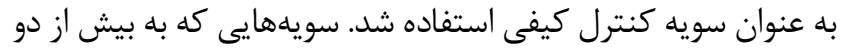
كلاس آنتىبيوتيك مقاومت نشان دادند به عنوان سويههاى MDR

معرفى شدند.
عفونتهاى حاد، به ويزه در بيماران بدحال است به طورى كه امروزه،

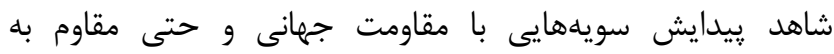
كوليستين بوده كه درمان عفوتهاى ناشى از اين باكترى را با با باليا محدوديت جدى مواجه كرده است (1)). شناسايى سريع سويههاى

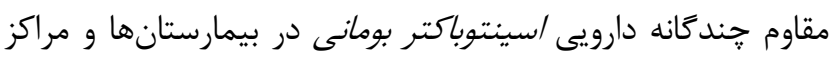

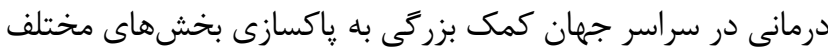
بيمارستانها از وجود جنين سويههايى مى كند. هدف از مطالعه حاضر براي

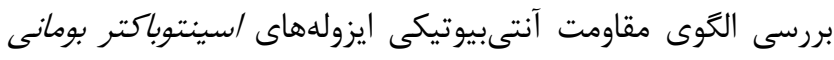

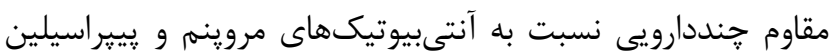

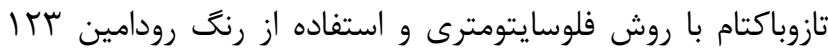

\section{مواد و روشها جمع آورى نمونه}

اين مطالعه مقطعى-توصيفى روى • بr نمونه بالينى شامل تراشه و زخم بيماران بسترى در بخشهاى بيمارستان ميلاد تهران به دانه

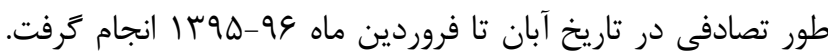

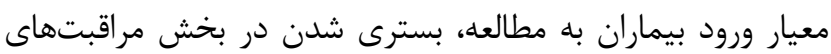

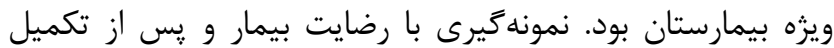

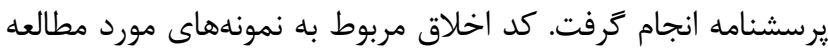

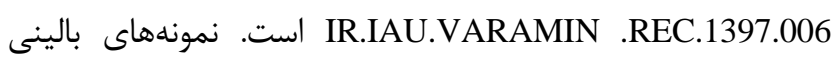
روى محيطهاى كشت بلاد آكار و مككانكى آكار، به منظور شناسايى نماليى

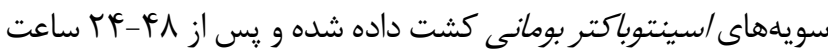

جدول ا. تعيين الكوى مقاومت ايزولههاى /سينتوباكتر بومانى بر اساس اندازه قطر هاله عدم رشد اطراف آنتىبيوتيكها بر اساس استاندارد

\begin{tabular}{|c|c|c|c|c|c|}
\hline SYMBOL & Antimicvobial Agent & DISK (田) & S & $\mathrm{I}$ & $\mathrm{R}$ \\
\hline مروينم (MEN) & Meropenem (Carbapenem) & 1. & > & $t \cdot-t t$ & $<19$ \\
\hline سيبروفلوكساسين & Ciprofloxacin (Fluoroquinolones) & $\Delta$ & $>r$ & $r-4$ & $<10$ \\
\hline جنتاميسين (GM) & Gentamycin (AMINOGLYCOSIDES ) & 1. & $>10$ & $\mid r-1 F$ & $<14$ \\
\hline (PIP-T) & Piperacillin-Tazobactam (Beta lactam) & $1 \cdots / 1$ & $>r$ & $M-r$ & $<I V$ \\
\hline لووفلوكساسين (levofloxacin) & Fluoroquinolones & $\Delta$ & $>19$ & $11-10$ & $<1$. \\
\hline تتراسايكلين (TE) & Tetracyclin (Tetracycline ) & r. & $>10$ & $\mid r-1 F$ & $<11$ \\
\hline ايمى ينه (IPM) & Imipenem (Carbapenem) & $1 \cdot$ & $>11$ & $\mid f-I V$ & $<14$ \\
\hline
\end{tabular}

براى تعيين MIC آنتىبيوتيكهاى مروينه و وبييراسيلين، تازوباكتام (سيخما، آمريكا) تهيه شده و رقتهاى مختلف آنتىبيوتيكها

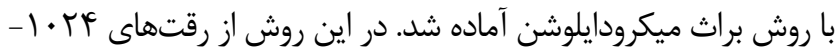

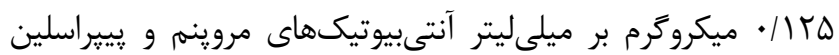

minimum ( تعيين حداقل غلظت مهاركننده رشد آنتىبيوتيك هاى مروينم و (inhibitory concentration (MIC) يبراسيلين - تازوباكتام 
براى انجام فلوسايتومترى نمونه كنترل منفى شامل سلولهاى كشته شده

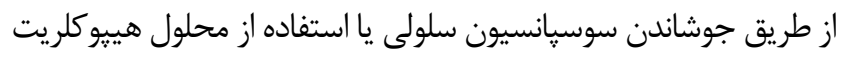
سديم به مدت • ا دقيقه بود.

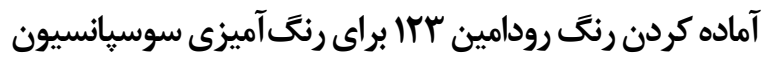

باكتريايى

مقدار r ميكروگرم بر ميلىليتر رودامين ب آ در محلول (Mm)

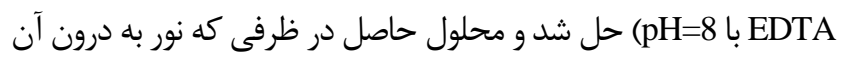

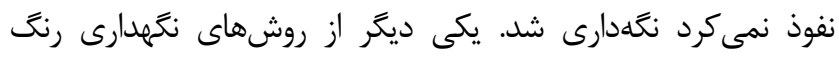

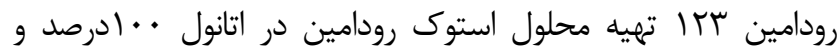

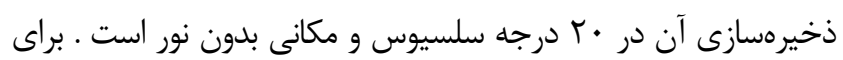

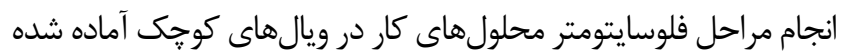
و در يخ قرار داده مىشوند تا كمترين ميزان تخريب در رنت صورت كيرد.

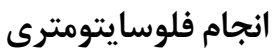

يس از انجام كليه مراحل فلوسايتومترى شامل فيكس كردن

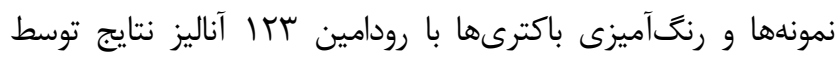
دستكاه فلوسايتومتر نوع Becton ) Face calibure Flocytometer Dickinson باكترىهاى زنده و مرده/سينتوباكتر بومانى و باكترى E.coli به عنوان

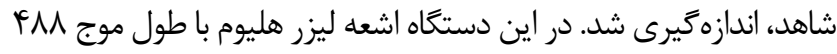

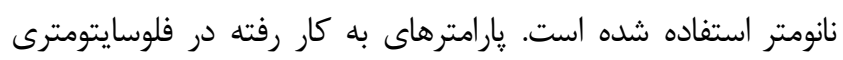

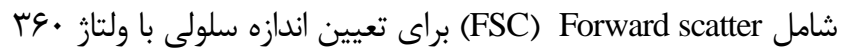

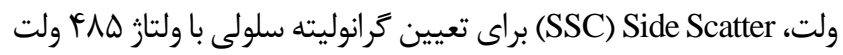

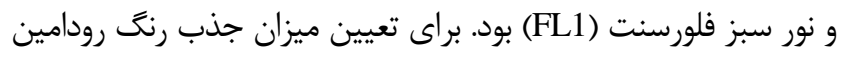

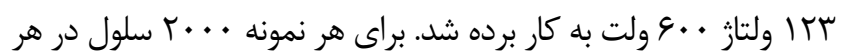

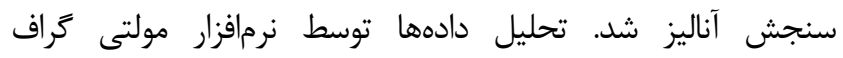

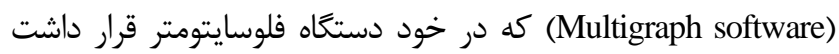
انجام كرفت. اختلاف بين فلورسنت سبز و Fc از طريق Multiparameter Data Analysis Software

\section{تحليل آمارى}

از آمار توصيفى شامل فراوانى، درصد ميانگين، انحرافمعيار براى شرح و توصيف دادها استفاده شد. براى درائ (Standard Deviation)

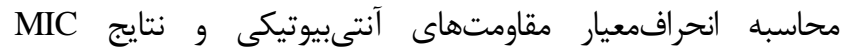

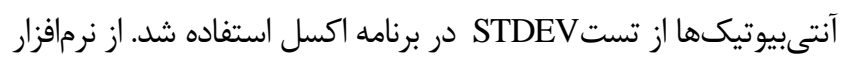

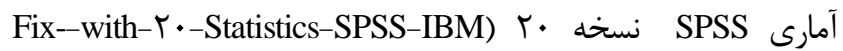
و و براى مقايسه اعداد از آزمون كاى اسكوئر استفاده
تازوباكتام استفاده شد. ‥ ميكروليتر محيط كشت مولرهينتون براث

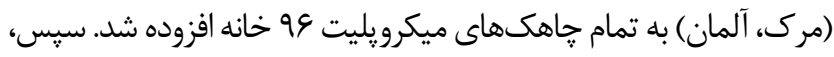

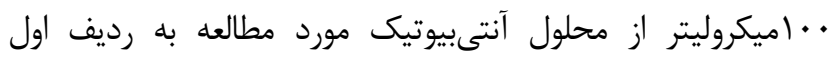

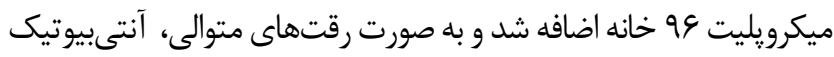

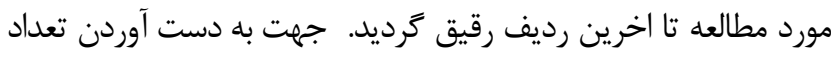

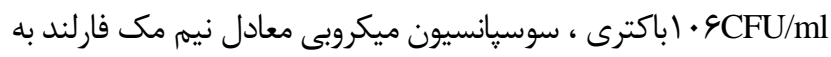

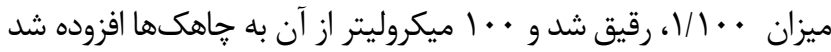

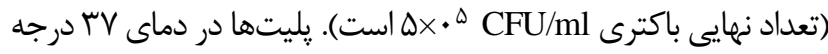

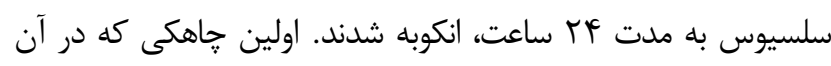
رشدى مشاهده نشد به عنوان حداقل غلظت مهارى باكترى (MIC)

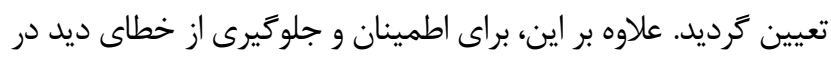

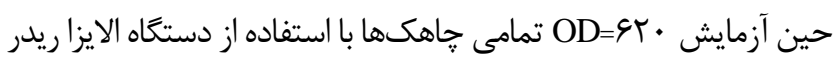

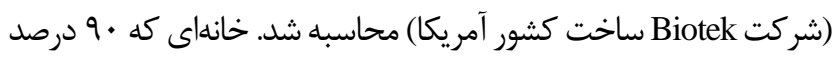
كاهش در جذب نورى حاصل از رشد باكترى را نشان داد، غلظت إنائ MIC90

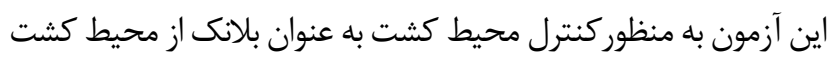
خالى (بدون آنتىبيوتيك و سلول باكترى) استفاده كرديد.

\section{فلوسايتومترى و تعيين زنده بودن باكتريايى در حضور

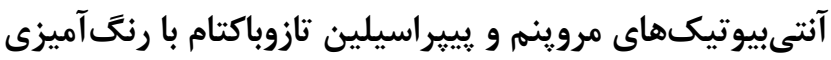

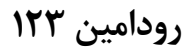

\section{آمادهسازى نمونه باكتريايى براى انجام فلوسايتومترى}

ابتدا سوسيانسيون نيم مك فارلند از • ا جدايه باكترى/سينتوباكتر بومانى مقاوم جند دارو و باكترى/شريشيا كلى ATCC TQ9TY به عنوان

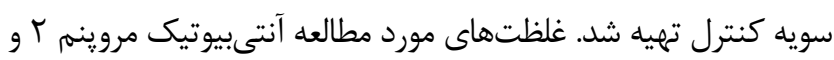

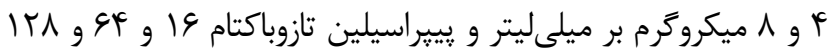

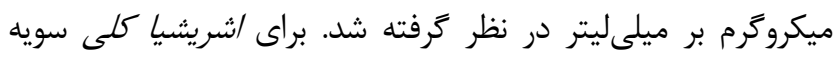

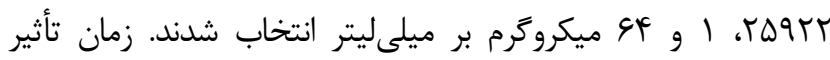

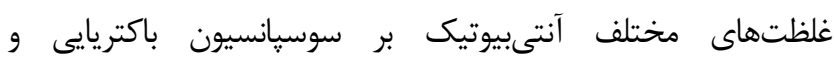

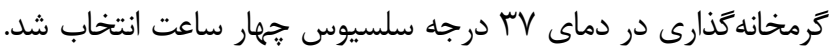

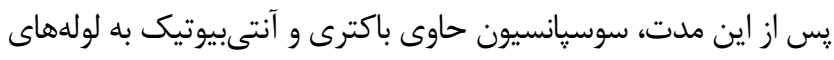

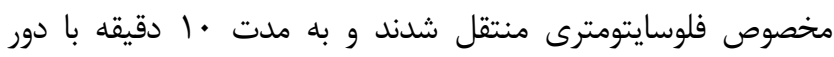

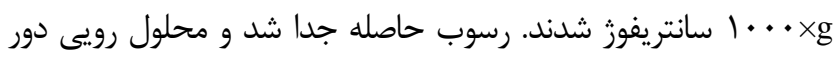

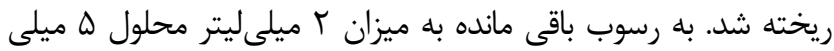

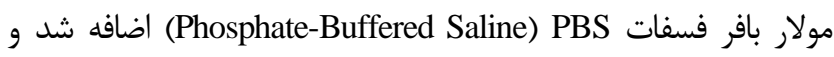

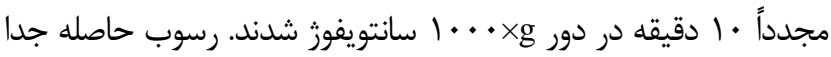

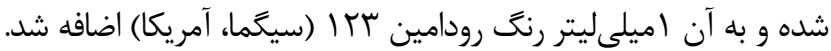


آلمان)، اوره (شركت مرك، آلمان)، و تستهاى OF، لايزين، بايل

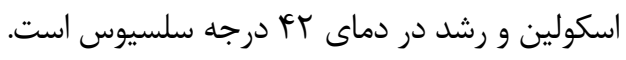

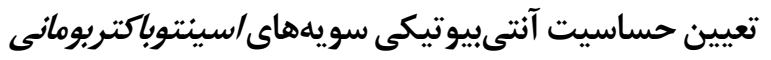

با توجه به نتايج به دست آمده (شكل ()، ميانكَين مقاومت

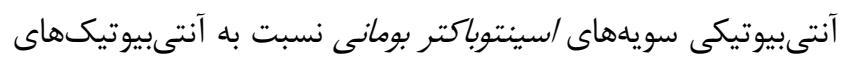

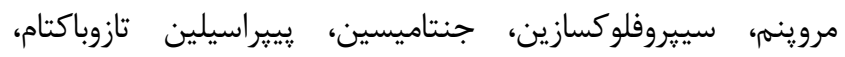

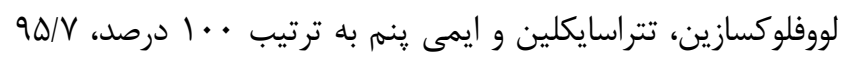

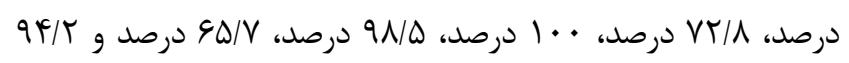

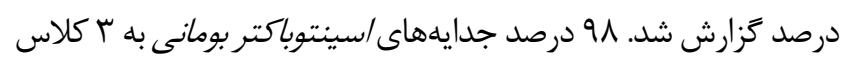

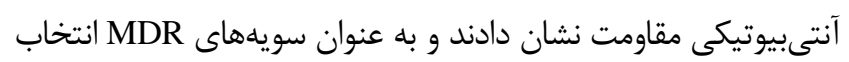

شدند.
شد. سطح معنادارى كمتر از ه• • • در نظر كرفته شد. به منظور ارزيابى

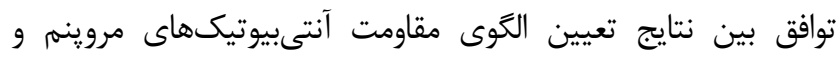

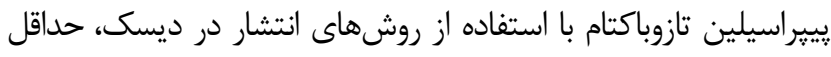
غلظت مهاركننده رشد يا MIC و فلوسايتومترى از روش معيار توافق يا روشاي (CA) Category Agreement

بافتهها

تعداد فه جدايه /سينتوباكتر بومانى از نمونههاى بالينى مورد مطالعه با انجام تستهاى بيوشيميايى جداسازى و شناسايى شدند.

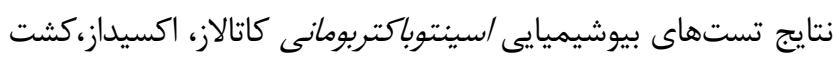
در محيطهاى TSI (شركت مرك، آلمان)، MRVP (شركت مرك،

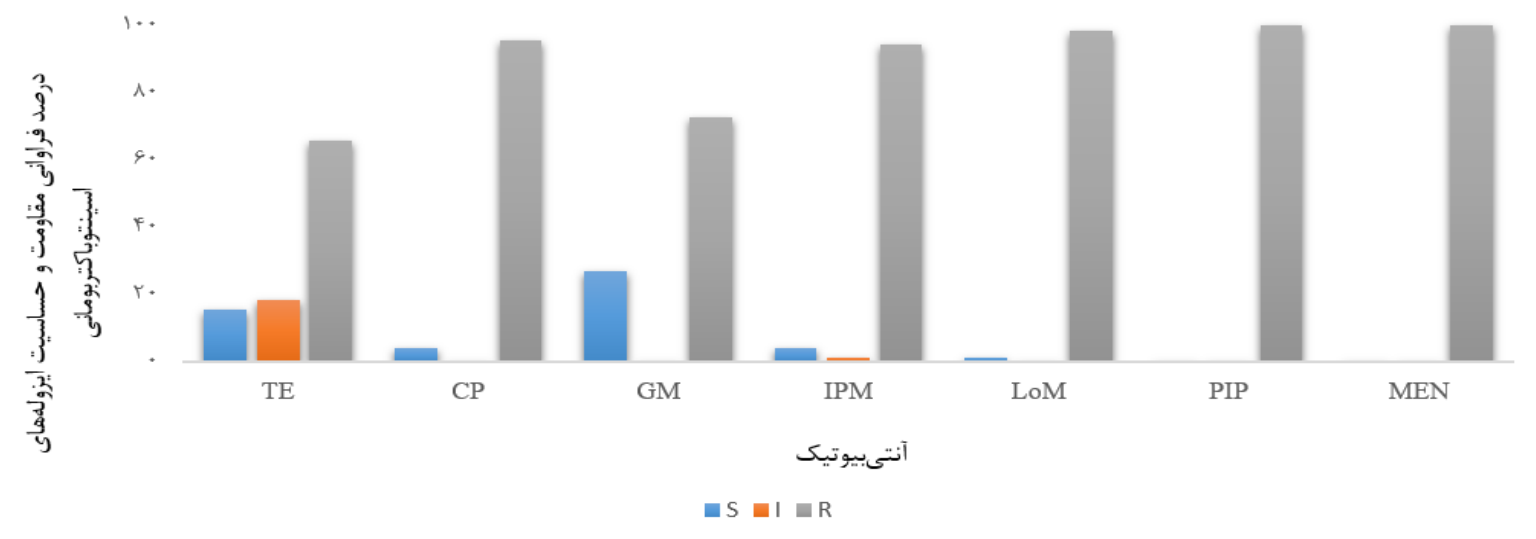

شكل 1. نمودار توزيع فراوانى مقاومت آنتىبيوتيكى ايزولههاى /سينتوباكتر بومانى

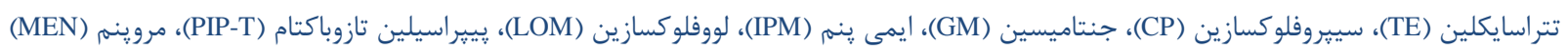

بررسى الكوى مقاومت اسينتوباكتر بومانى به به آنتىبيوتيك مروينهم با دستگًاه فلوسايتومترى برى

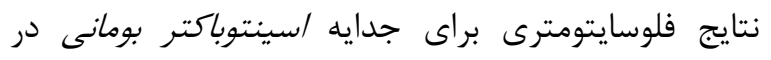

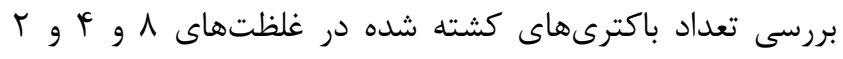

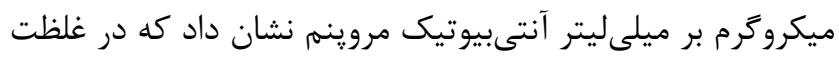
^ ميكرو گرم بر ميلىليتر كه هيستو شكل r-الف نشان داده شده است، ميزان سلولهاى كشته شدو شده

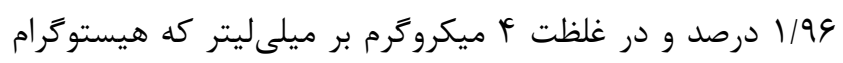

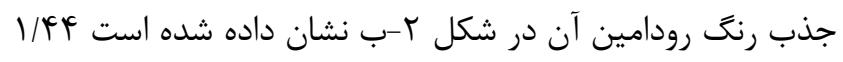

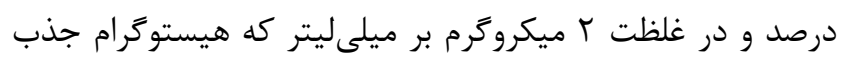
رنت رودامين آن در شكل r-ج نشان داده شده ها • درصد است.

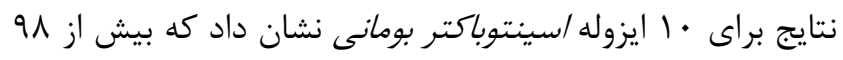
درصد باكترىها در غلظتهاى مورد مطالعه مروينهم مقاومت نشان

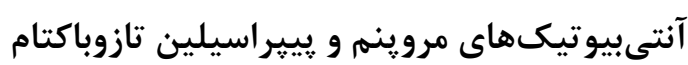

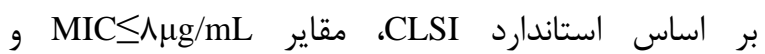

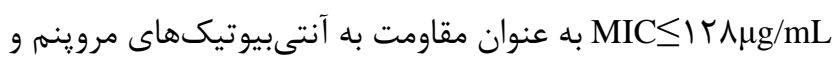

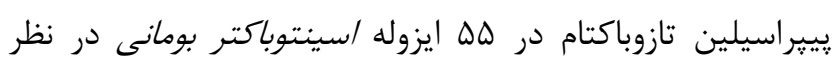

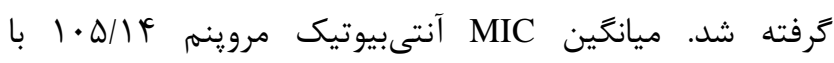

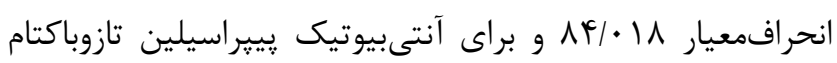
|| سويهها، براى آنتىبيوتيك مروينه

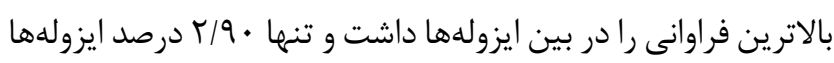
Mg/mL^ MIC

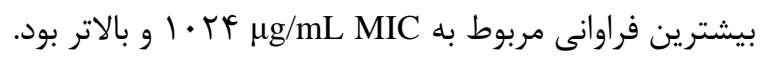




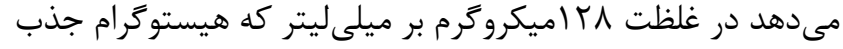

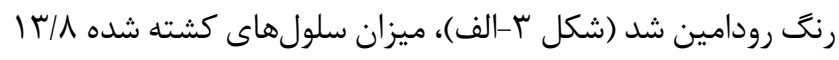

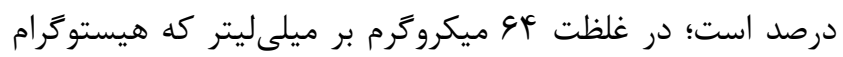

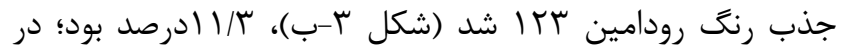

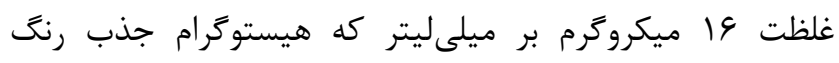

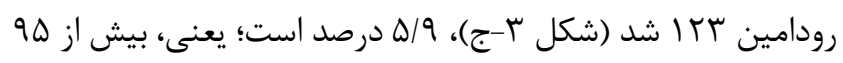

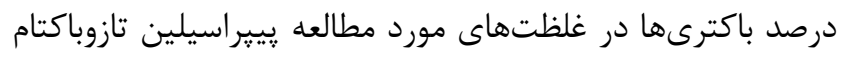
مقاومت نشان دادند. با اين حال، يك كاهش تعداد باكترى زنده باد باديا افزايش غلظت آنتى بيوتيك مشاهده شد.

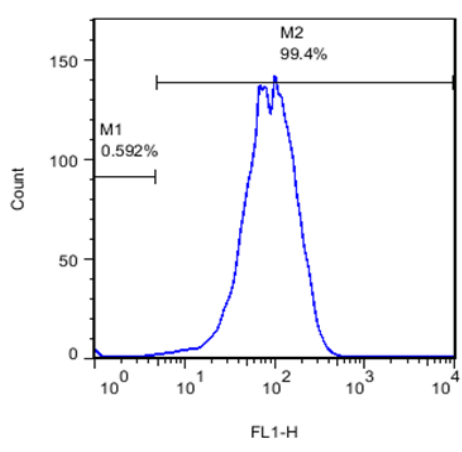

(ج)

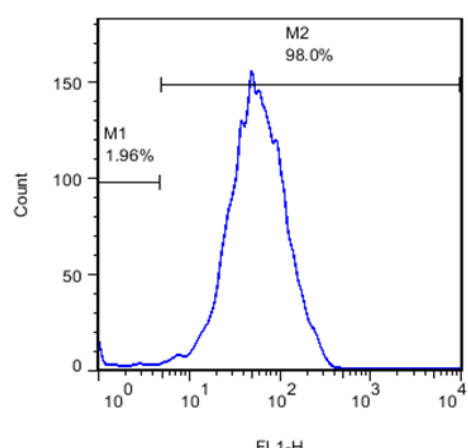

(ب)

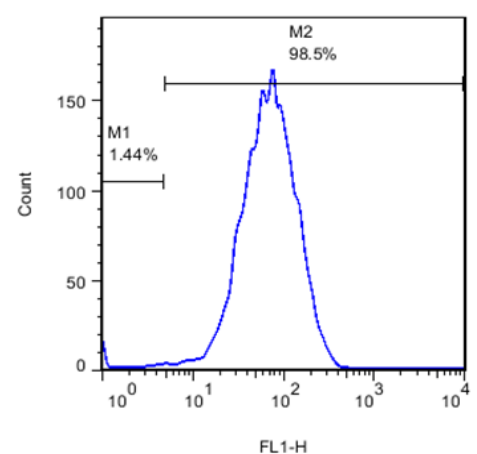

(الف)

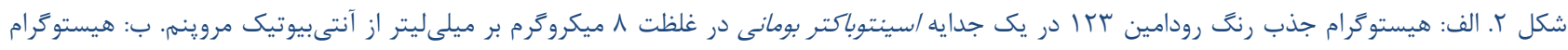

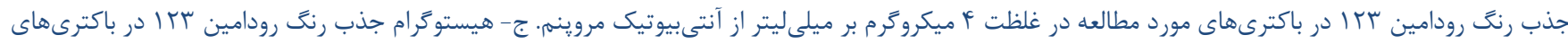

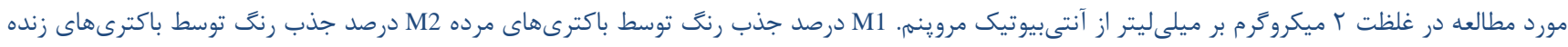

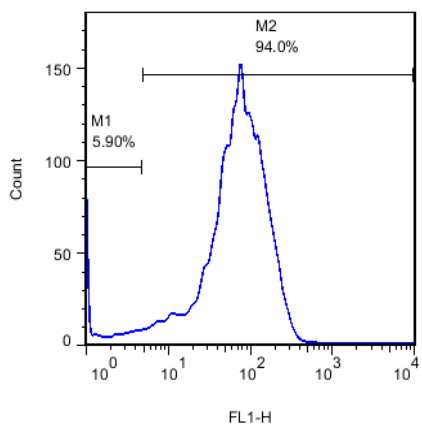

(ج)

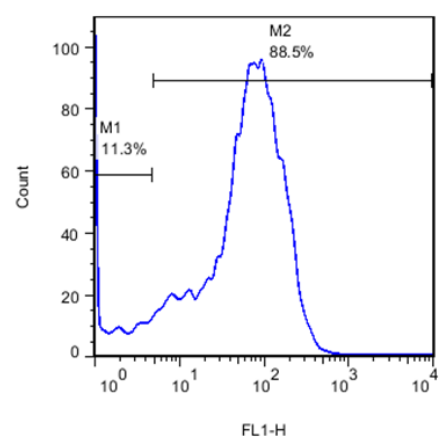

(ب)

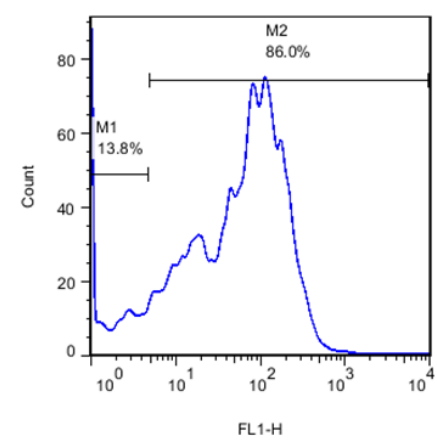

(الف)

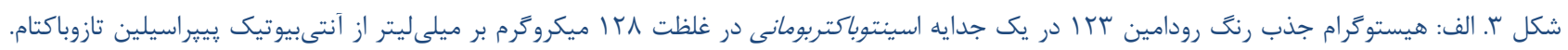

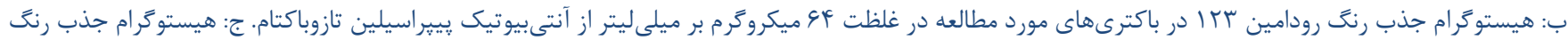

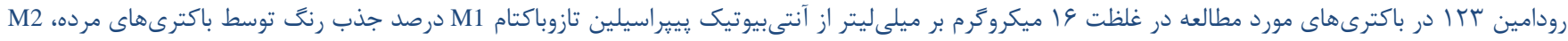
درصد جذب رنخ توسط باكترى هاى زنده. 
غلظتهاى عاميكروگرم بر ميلىليتر آنتىبيوتيك يبيراسيلين تازوباكتام كه هيستوگرام جذب رنت رودامين رودامين شده است

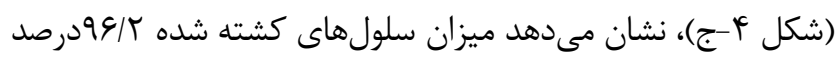
است و فقط أدرصد سلولها زنده ماند دهد ميرن سندان ״س از بررسى نتايج فلوسايتومترى براى تعيين الخوى

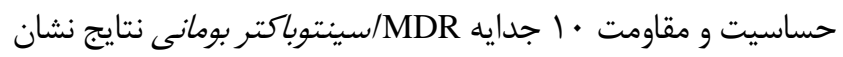
داد كه بيش از هو درصد سلولها پس از تأثير غلظتهاى مورد مطالعه

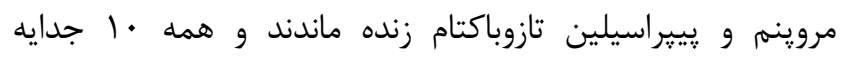
اسينتوباكتر بومانى نسبت به آنتىبيوتيكهاى مروينهم و پِيِيراسيلين تازوباكتام با روش فلوسايتومترى مقاومت نشان داد. مقايسه نتايج تعيين الكوى مقاومت آنتىبيوتيكى با هر سه روش و بروسى دمى معيار توافق بين روشها در نهايت CA ل . ادرصد براى هر دو آنتىبيوتيك كزارش شد.

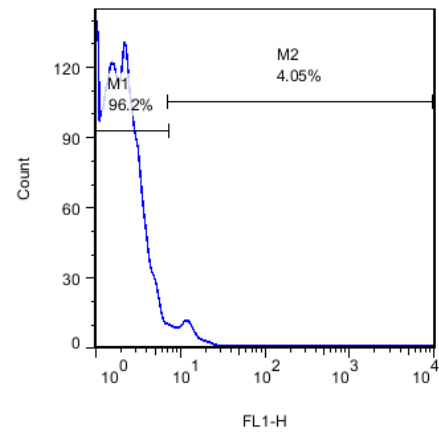

(ج)

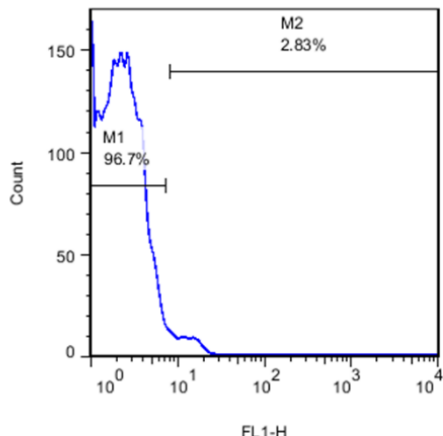

(ب)

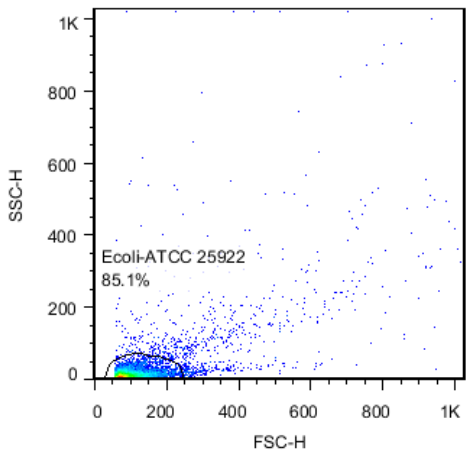

(الف)

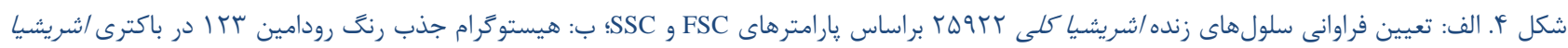

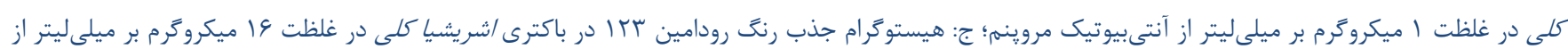
آنتىبيوتيك קِيير ايسلين تازوباكتام.

مىشود و منجر به مرى و مير بالغ بر سזدرصد بيماران بسترى در

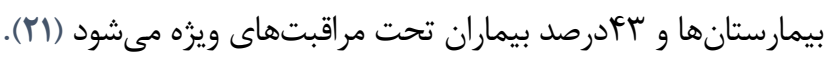

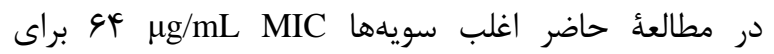

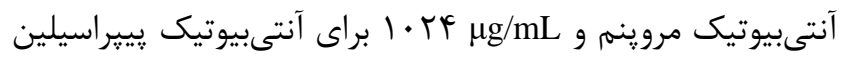
تازوباكتام داشتند كه نشان از مقاومت بسيار بالاى سويههاى

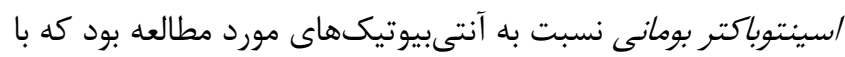

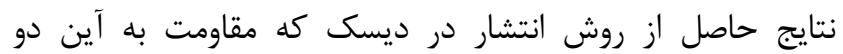

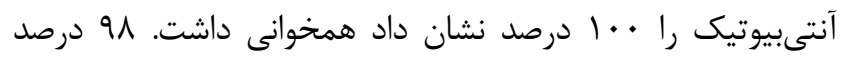

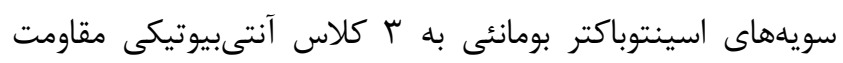
نشان دادند و به عنوان سويههاى MDR انتخاب شدند. نتايج اين

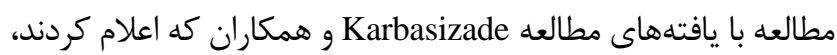

\section{نتايج بررسى الكوى مقاومت سويه/شريشيا كلى TAYT}

به عنوان شاهد نسبت به آنتىبيوتيكهاى مروينهم و بروسي

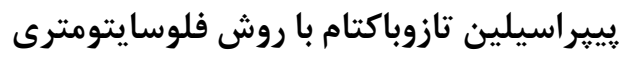

در نمودار نقطهاى تهيه شده از سوسيانسيون حاوى باكترى

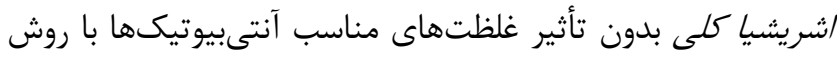
فلوسايتومترى و يارامترهاى FSC و SSC، ميزان سلولهاى زائ زنداي

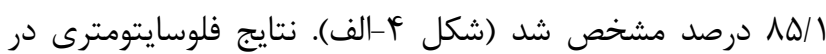
بررسى تعداد باكترىهاى كشته شده /شريشيا كلى در غلظتهاى

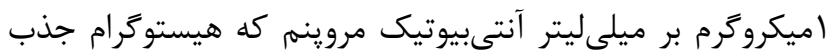

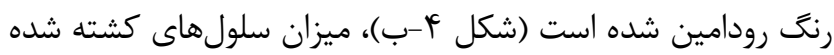

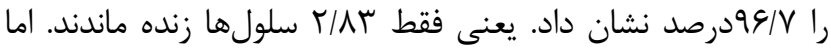

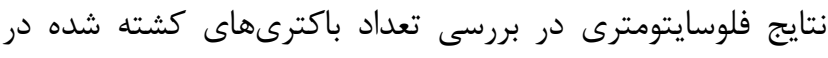




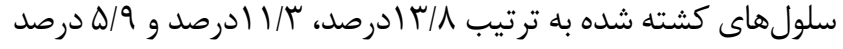

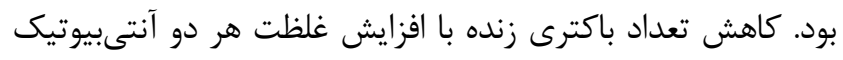

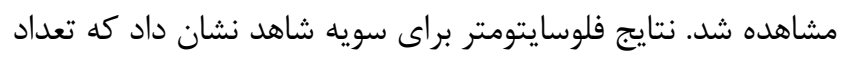

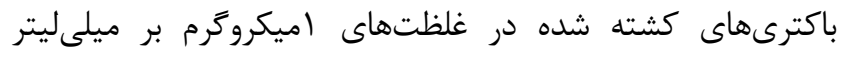

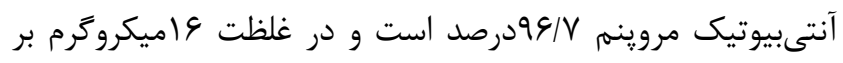

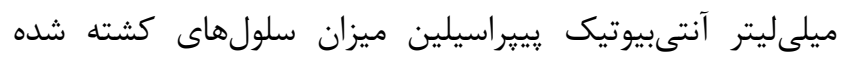
ك9/

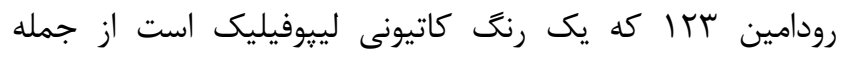

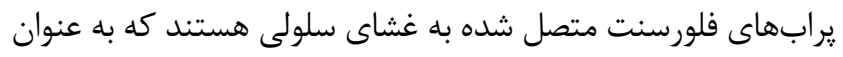
تركيباتى براى سنجش اثرات دارويى توسط فلوسايتومتر استفاده شده

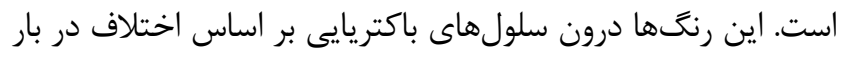

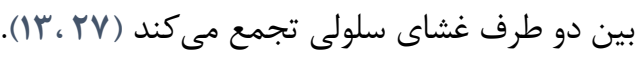

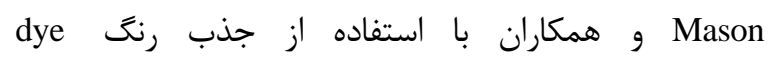

Fc rbisdibutylbarbituric acid) trimethine oxonol فلوسايتومتر توانستند تأثير آنتىبيوتيكهاى آميىسيلين،

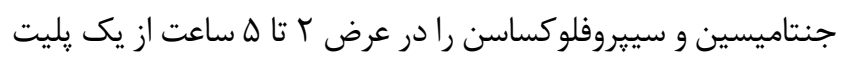

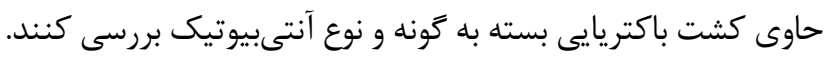

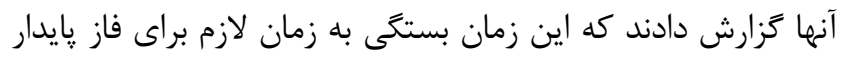

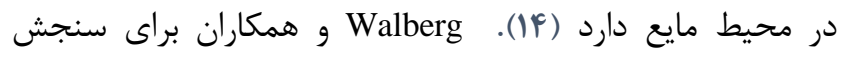

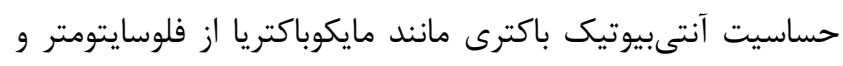

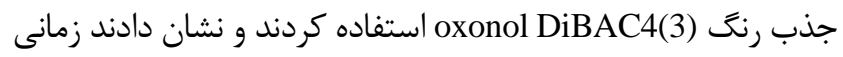
كه صرف اين سنجش شد در مقايسه با روش راديواكتيو نشاندار

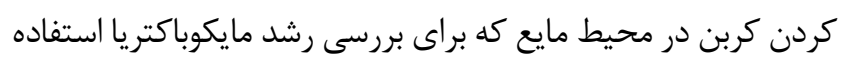

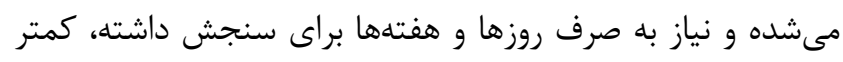

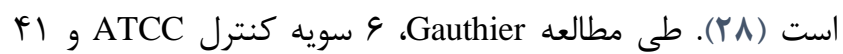

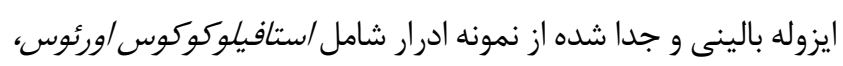

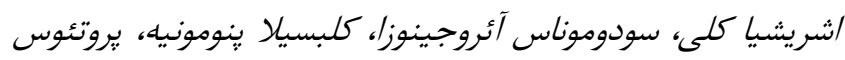
مير/بيليس، انتروكوكوس فكاليس و /ستفايلوكوكس /بيدرميتيس و وتئيس

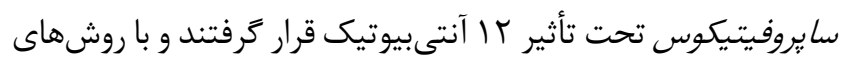

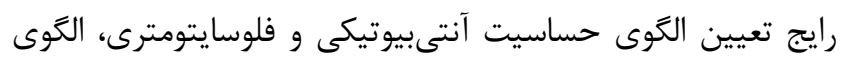

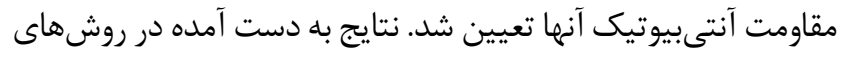

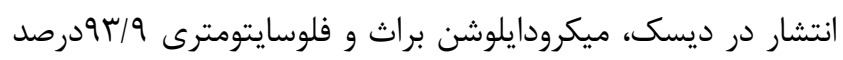

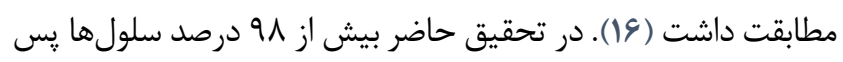

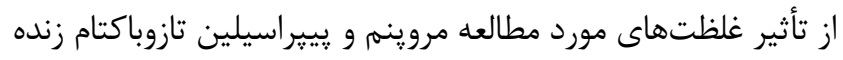

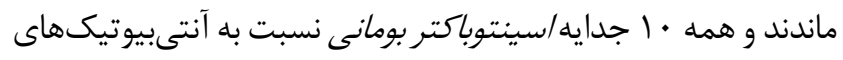

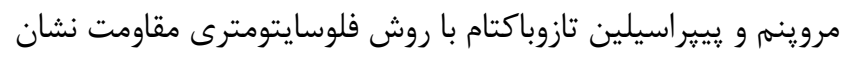

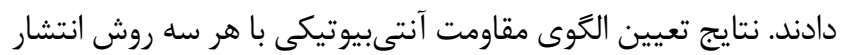

اكثر سويههاى /سينتوباكتر بومانى جدا شده در ايران نسبت به داروهاى خط اول درمان شامل آمينوكليكوزيدها (جنتامايسين،

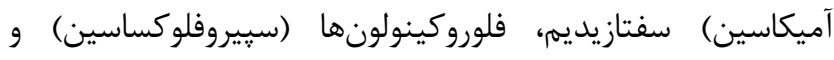

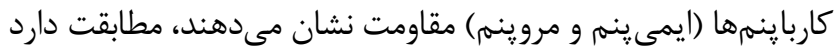

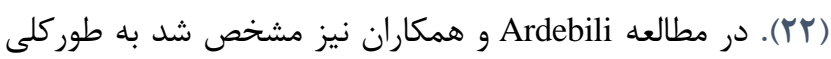

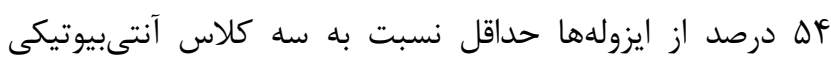
مقاومت مقاومت MDR نشان دادند و فراوانى مقاومت نسبت به إنها

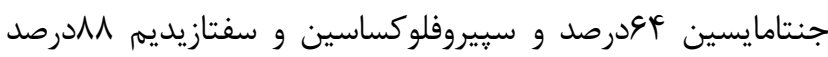

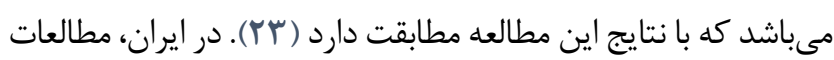

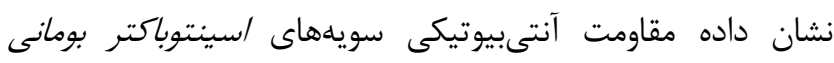

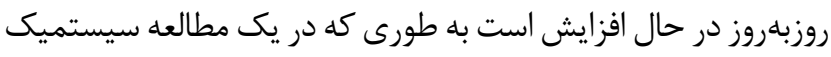

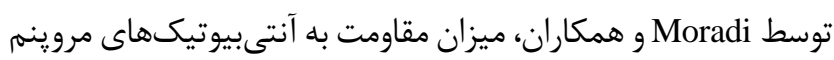

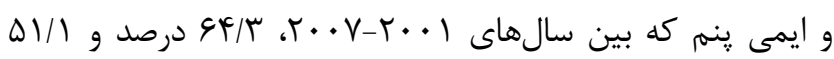

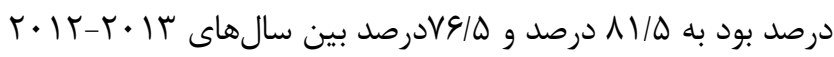

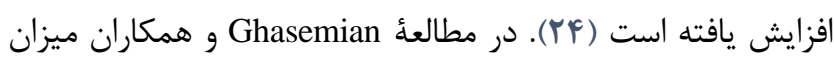

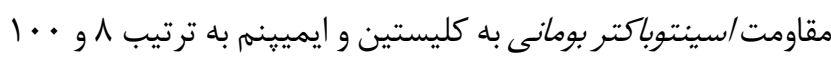

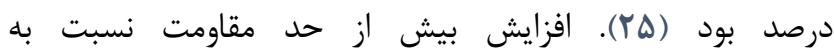

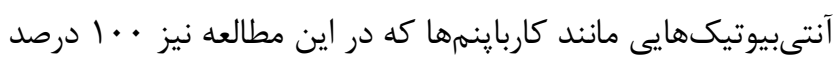

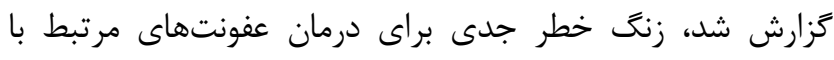

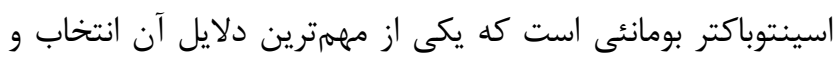

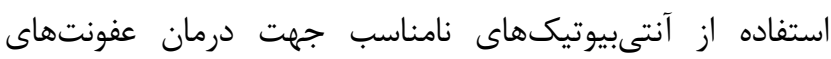

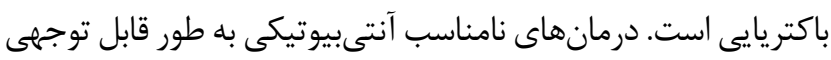

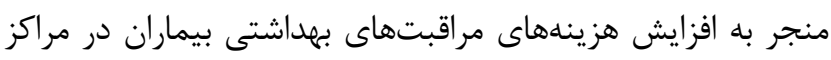

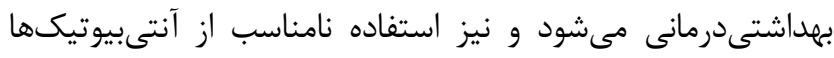

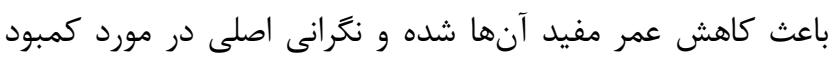

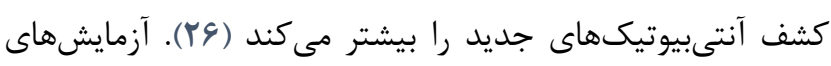

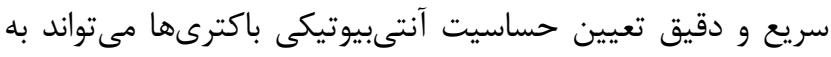

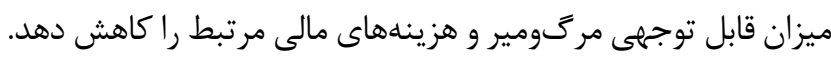

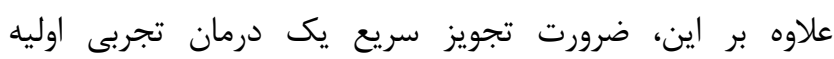
ضدميكروبى زمانى كه يزشك در انتظار كسب نتايج تست حساسيت برون

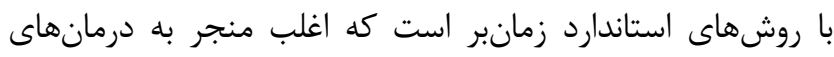
نامناسب مىشود بسيار اهميت دارد. در اين تحقيق با روش فلوسايتومترى و با استفاده از رنى إنى

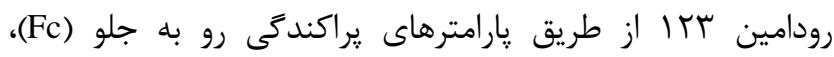

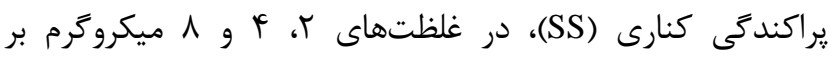

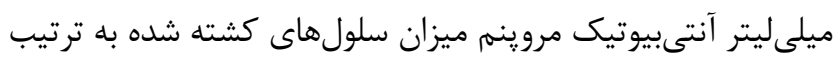

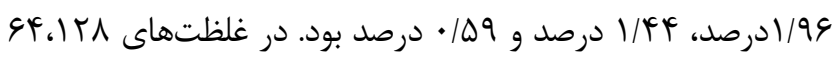

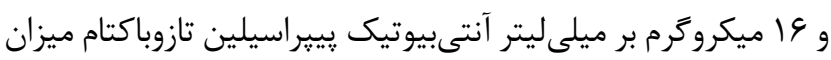


دهد. درحاليكه كاركنان طى روندهاى تست حساسيت مراحل

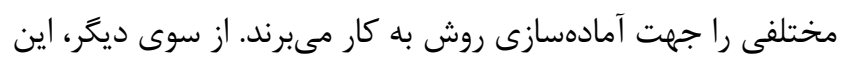

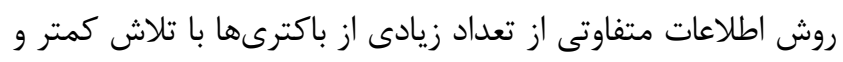

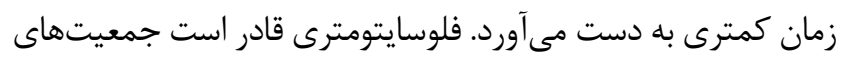

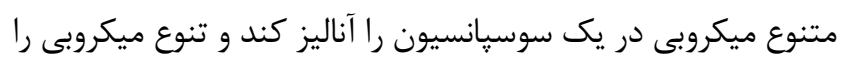

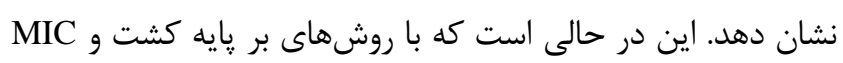
جمعيتهاى مختلف ميكروبى در كشت قابل تمايز نيستند. كوتاه

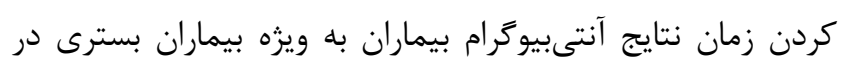

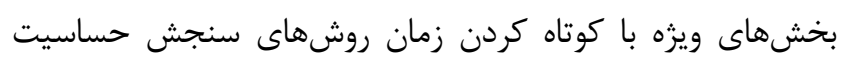

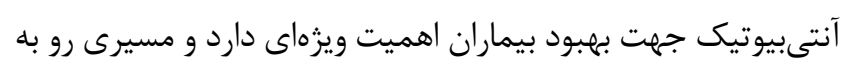

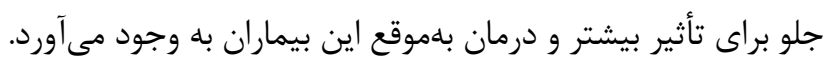

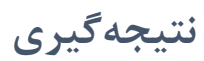

نتايج تعيين الكَوى مقاومت آنتىبيوتيكى با روش فلوسايتومترى سيرى

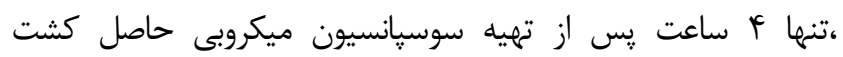

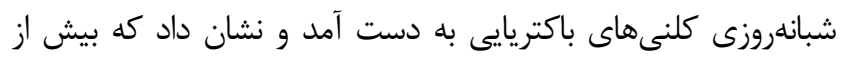

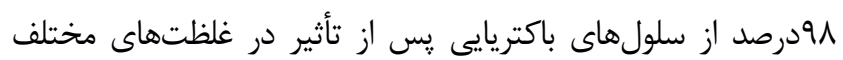

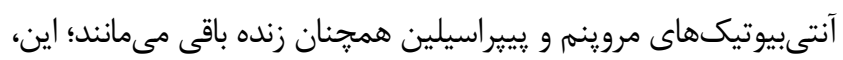

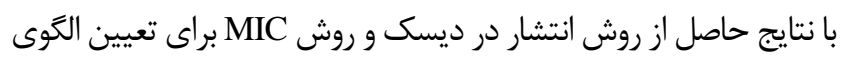

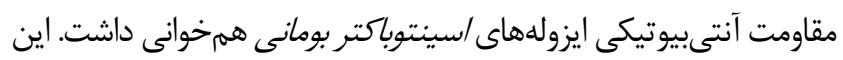

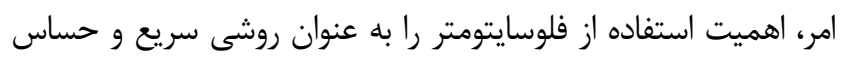

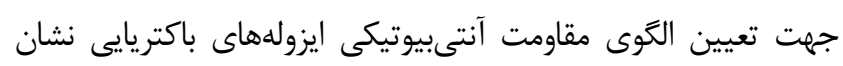

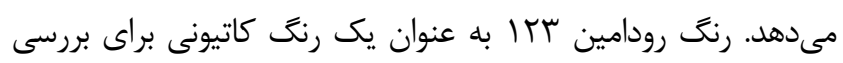

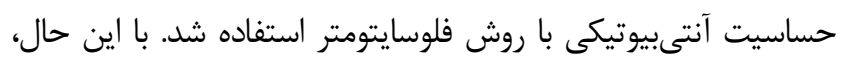

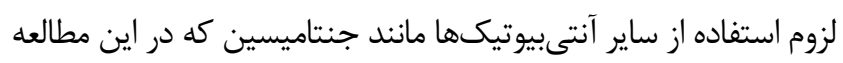

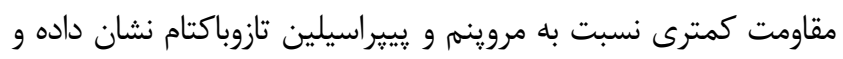

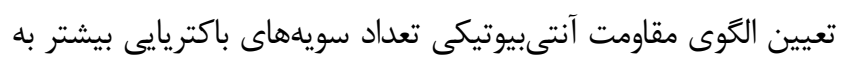

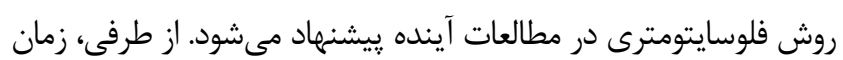

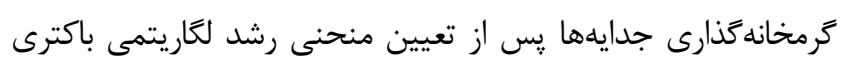

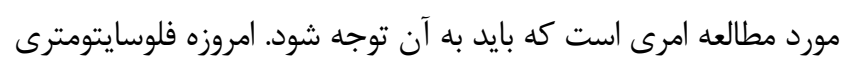

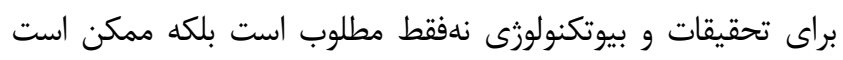

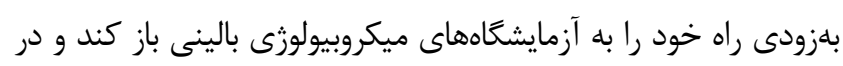

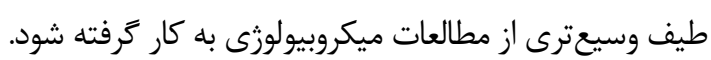

\section{سياسَز ارى}

بدينوسيله از جناب آقاى اميد حسينى كارشناس آزمايشعاه

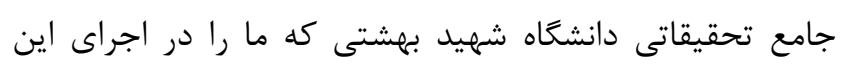
يزوهش يارى كردند، تقدير و تشكر مىشود.
در ديسك، ميكرودايلوشن براث و فلوسايتومترى و بررسى معيار توافق

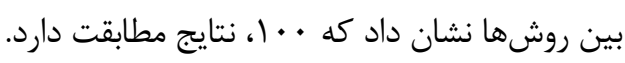

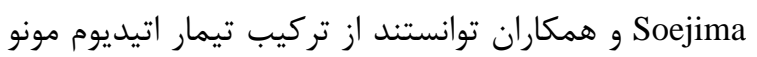

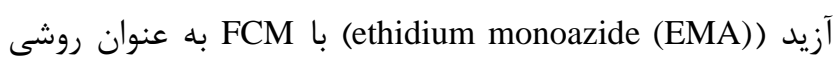
سريع براى تمايز بين سلولهاى زنده و آسيبديده باكترى ليستريا

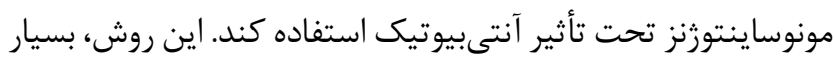

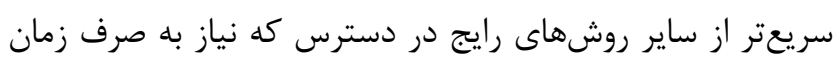

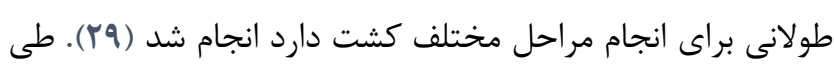

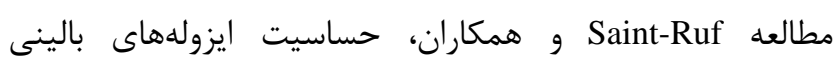
باكترىهاى گرم منفى اشريشيا كلى و سودوموناس ائروزينوزا را با با ليا

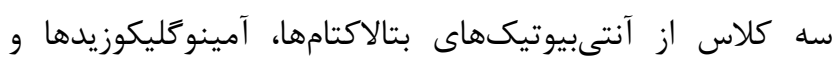

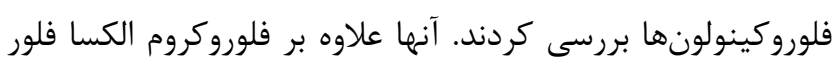

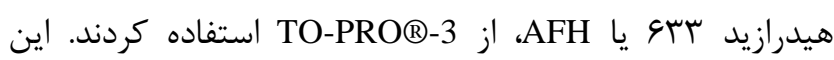

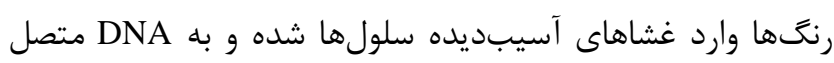
مىشوند. در آن مطالعه روش فلوسايتومترى روشى برآ براى اثبات

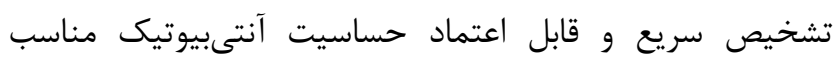

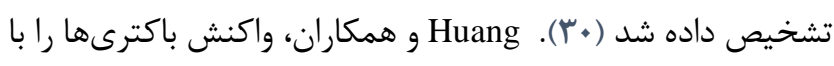

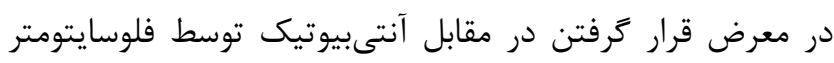

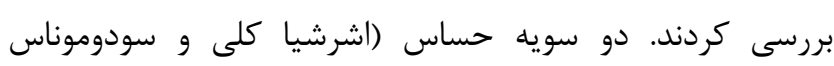
ائروزينوزا) و يكى سويه مقاوم جنداردارويى (ايزوله بالينى اشريشيا

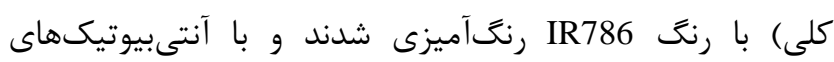
باكتريواستاتيك براى شناسايى تغييرات وارد شده در بر محدوده

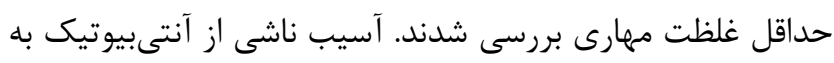

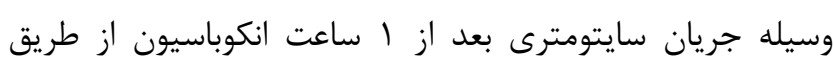

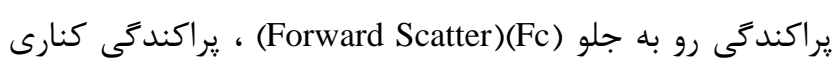
) و كانالهاى فلورسنس ديده شد. اختلاف (Side Scatter )(SS)

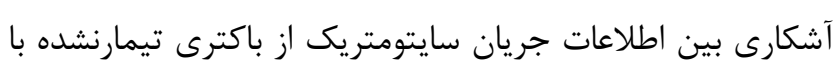

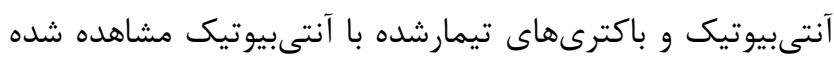

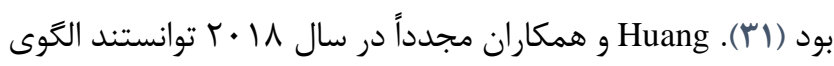

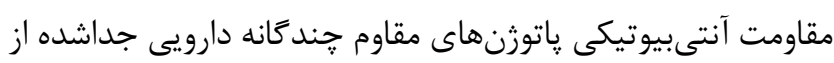

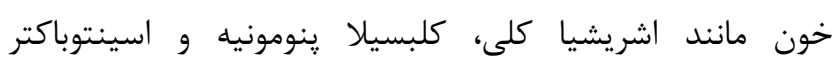

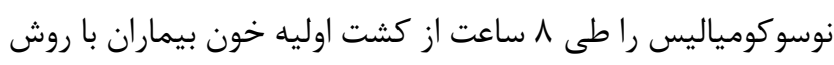

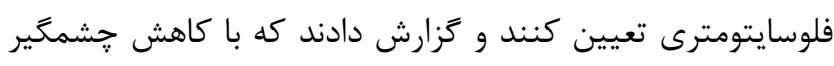

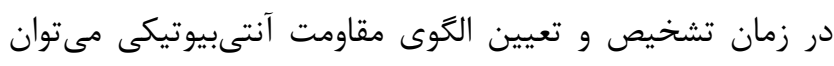

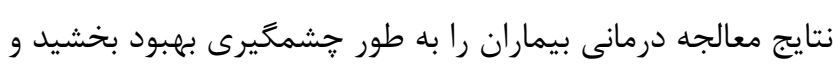

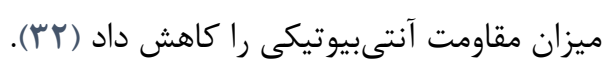

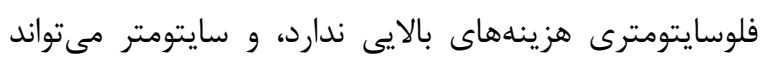
بسيارى از مراحل بييت كردن و شستشو را به صورت اتوماتيك انجام 


$$
\text { بين نويسند تارن تعارض منافع در منافع ززارش نشده است. }
$$

1. Veal DA, Deere D, Ferrari B, Piper J, Attfield PV. Fluorescence staining and flow cytometry for monitoring microbial cells. Journal of Immunological Methods. 2000; 243:220-191. [DOI:10.1016/S00221759(00)00234-9]

2. Nuding S, Zabel LT. Detection, identification, and susceptibility testing of bacteria by flow cytometry. Journal of Bacteriology \& Parasitology. 2013; S5005. Doi: 10(4172):2155-9597 [DOI:10.4172/21559597.S5-005]

3. Kansanaho $\mathrm{H}$, Isonen-Sjölund $\mathrm{N}$, Pietilä $\mathrm{K}$, Airaksinen M, Isonen T. Patient counselling profile in a Finnish pharmacy. Patient Education and Counseling. 2002; 47(1):77-82. [DOI:10.1016/S0738 -3991(01)00180-X]

4. Huang TH, Ning X, Wang X, Murthy N, Tzeng YL, Dickson RM. Rapid cytometric antibiotic susceptibility testing utilizing adaptive multidimensional statistical metrics. Analytical chemistry. 2015; 87(3):1941-9. [DOI:10.1021/ac50 4241x] [PMID] [PMCID]

5. Wu L, Wang $\mathrm{S}$, Song $\mathrm{Y}$, Wang $\mathrm{X}$, Yan $\mathrm{X}$. Applications and challenges for single-bacteria analysis by flow cytometry. Science China Chemistry. 2016; 59(1):30-9. [DOI:10.1007/s11426015-5518-3]

6. Fraser D, Kaern M. A chance at survival: gene expression noise and phenotypic diversification strategies. Molecular Microbiology. 2009; 71(6):1333-40. [DOI:10.1111/j.13652958.2009.06605.x] [PMID]

7. Rainey PB, Beaumont HJ, Ferguson GC, Gallie J, Kost C, Libby E, et al. The evolutionary emergence of stochastic phenotype switching in bacteria. 2011. 2011; 10(Suppl 1):S14. [DOI:10.1186/1475-2859-10S1-S14] [PMID] [PMCID]

8. Paau AS Cowles JR, Oro J. Flow-microfluorometric analysis of Escherichia coli, Rhizobium meliloti, and Rhizobium japonicum at different stages of the growth cycle. Canadian journal of microbiology. 1977; 23(9):1165-9. [DOI:10.1139/m77-175] [PMID]

\section{References}

9. Hutter KJ, Eipel H. Microbial determinations by flow cytometry. Microbiology. 1979; 113(2):369-75. [DOI:10.1099/00221287-113-2-369] [PMID]

10. Haugland RP. Handbook of fluorescent probes and research chemicals. Eugene: Molecular Probes Inc.; 1996.

11. Shapiro HM. Microbial analysis at the single-cell level: tasks and techniques. Journal of Microbiological Methods. 2000; 42(1):3-16. [DOI:10.1016/S0167-7012(00)00167-6]

12. Sack U, Tárnok A, Rothe G. Cellular diagnostics: basic principles, methods and clinical applications of flow cytometry. Basel: Karger Medical and Scientific Publishers; 2009. [DOI:10.1159/isbn.978-3-80558556-9]

13. Suller M, Stark J, Lloyd D. A flow cytometric study of antibiotic-induced damage and evaluation as a rapid antibiotic susceptibility test for methicillinresistant Staphylococcus aureus. The Journal of antimicrobial chemotherapy. 1997; 40(1):77-83. [DOI:10.1093/jac/40.1.77] [PMID]

14. Mason D, Allman R, Stark J, Lloyd D. Rapid estimation of bacterial antibiotic susceptibility with flow cytometry. Journal of Microscopy. 1994; 176(1):8-16. 2818.1994.tb03494.x] [PMID]

15. Suller M, Lloyd D. Fluorescence monitoring of antibiotic-induced bacterial damage using flow cytometry. Cytometry: The Journal of the International Society for Analytical Cytology. 1999; 35(3):235-41.[DOI:10.1002/(SICI)1097-0320 (19990301) 35:33.0.CO;2-0]

16. Gauthier C, Pierre STY, Villemure R. Rapid antimicrobial susceptibility testing of urinary tract isolates and samples by flow cytometry. Journal of Medical Microbiology.2002; 51:192-200. [DOI:10.1099/0022-1317-51-3-192] [PMID]

17. Zilberberg MD, Nathanson BH, Sulham K, Fan W, Shorr AF. Multidrug resistance, inappropriate empiric therapy, and hospital mortality in Acinetobacter baumannii pneumonia and sepsis. Critical Care. 2016; 20(1):221. [PMID] [PMCID] 


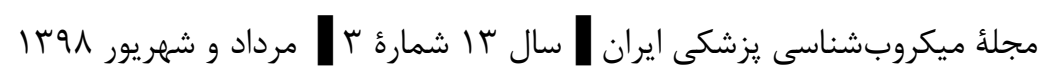

18. Visca $\mathrm{P}$, Seifert $\mathrm{H}$, Towner KJ. Acinetobacter infection-an emerging threat to human health. IUBMB life. 2011; 63(12):1048-54. [DOI:10.1002/iub.600] [PMID]

19. McConnell MJ, Actis L, Pachón J. Acinetobacter baumannii: human infections, factors contributing to pathogenesis and animal models. FEMS Microbiology Review. 2013; 37(2):130-55. [DOI:10.1111/j.1574-6976.2012.00344.x] [PMID]

20. Falagas ME, Karveli EA.The changing global epidemiology of Acinetobacter baumannii infections: a development with major public health implications. Clinical Microbiology and Infection. 2007; 13(2):117-9. [DOI:10.1111/j.1469-0691.2006 .01596.x] [PMID]

21. Falagas ME, Bliziotis IA, Siempos II. Attributable mortality of Acinetobacter baumannii infections in critically ill patients: a systematic review of matched cohort and case-control studies. Critical Care. 2006; 10(2):R48. [DOI:10.1186/cc4869] [PMID] [PMCID]

22. Karbasizade V, Heidari L. Antimicrobial resistance of Acinetobacter baumannii isolated from Intensive Care Units of Isfahan hospitals, Iran. Journal of Isfahan Medical School. 2012; 30(191).

23. Ardebili A, Lari AR, Talebi M. Correlation of ciprofloxacin resistance with the AdeABC efflux system in Acinetobacter baumannii clinical isolates. Annals of Laboratory Medicine. 2014; 34(6):433-8. [DOI:10.3343/alm.2014.34.6.433] [PMID] [PMCID]

24. Moradi J, Hashemi FB, Bahador A. Antibiotic resistance of Acinetobacter baumannii in Iran: a systemic review of the published literature. Osong Public Health and Research Perspectives.2015;6(2):79-86. [DOI:10.1016/j.phrp.2014.12.006] [PMID] [PMCID]

25. Ghasemian R, Ahanjan M, Fatehi E, Shokri M. Prevalence and antibiotic resistance pattern of Acinetobacter isolated from patients admitted in ICUs in Mazandaran, Northern Iran. Global Journal of Health Science. 2016; 11(8):112-9. [DOI:10.5539/gjhs.v8n11p112]

26. Heinemann JA, Ankenbauer RG, Amábile-Cuevas CF. Do antibiotics maintain antibiotic resistance? Drug Discovery Today. 2000; 5(5):195-204. [DOI:10.1016/S1359-6446(00)01483-5]

27. Comas J,Vives-Rego J. Assessment of the effects of gramicidin, formaldehyde, and surfactants on Escherichia coli by flow cytometry using nucleic acid and membrane potential dyes. Cytometry.1997; 29:58-64.[DOI:10.1002/(SICI)1097-0320(1997 0901)29:13.0.CO;2-9]

28. Walberg M, Steent HB. Flow cytometric monitoring of bacterial susceptibility to antibiotics. Methods in
Cell Biology. 2001; 64:553-66. [DOI:10.1016/S0091679X(01)64029-9]

29. Soejima T, Minami JI, Iwatsuki K. The exclusive use of flow cytometry to evaluate the antibioticsusceptibility. Biochimica et Biophysica Acta (BBA)General Subjects. 2012; 1820(12):1980-6. [DOI:10.1016/j.bbagen.2012.09.003] [PMID]

30. Saint-Ruf C, Crussard S, Franceschi C, Orenga S, Ouattara J, Ramjeet M, et al. Antibiotic susceptibility testing of the gram-negative bacteria based on flow cytometry. Frontiers in Microbiology. 2016; 7:1121. [DOI:10.3389/fmicb.2016.01121] [PMID] [PMCID]

31. Huang TH, Ning X, Wang X, Murthy N, Tzeng YL, Dickson RM. Rapid cytometric antibiotic susceptibility testing utilizing adaptive multidimensional statistical metrics. Analytical Chemistry. 2015; 87(3):1941-9. [DOI:10.1021/ac504241x] [PMID] [PMCID]

32. Huang TH, Tzeng Y, Land Dickson R. FAST: Rapid Determinations of Antibiotic Susceptibility Phenotypes using Label-Free. Cytometry Cytometry A . 2018; 93(6):63948. [DOI:10.1002/cyto.a.23370] [PMID] [PMCID] 